\title{
Transcripts within rod photoreceptors of the Zebrafish retina
}

\author{
Chi Sun, Carlos Galicia and Deborah L. Stenkamp* (D)
}

\begin{abstract}
Background: The purpose of this study was to identify transcripts of retinal rod photoreceptors of the zebrafish. The zebrafish is an important animal model for vision science due to rapid and tractable development, persistent neurogenesis of rods throughout the lifespan, and capacity for functional retinal regeneration.

Results: Zebrafish rods, and non-rod retinal cells of the xops:eGFP transgenic line, were separated by cell dissociation and fluorescence-activated cell sorting (FACS), followed by RNA-seq. At a false discovery rate of $<0.01$, 597 transcripts were upregulated ("enriched") in rods vs. other retinal cells, and 1032 were downregulated ("depleted"). Thirteen thousand three hundred twenty four total transcripts were detected in rods, including many not previously known to be expressed by rods. Forty five transcripts were validated by qPCR in FACS-sorted rods vs. other retinal cells. Transcripts enriched in rods from adult retinas were also enriched in rods from larval and juvenile retinas, and were also enriched in rods sorted from retinas subjected to a neurotoxic lesion and allowed to regenerate. Many transcripts enriched in rods were upregulated in retinas of wildtype retinas vs. those of a zebrafish model for rod degeneration.
\end{abstract}

Conclusions: We report the generation and validation of an RNA-seq dataset describing the rod transcriptome of the zebrafish, which is now available as a resource for further studies of rod photoreceptor biology and comparative transcriptomics.

Keywords: Rod photoreceptor, Retina, Transcriptome, RNA-Seq, Zebrafish, Regeneration

\section{Background}

Within the vertebrate neural retina, photoreceptor cells are the sensory neurons that detect photons and convert this physical information into electrochemical signals. Rod photoreceptors contain the visual pigment rhodopsin, are highly sensitive to light, and provide predominantly convergent information to downstream neurons to maximize light detectability in low-light situations. Cone photoreceptors contain cone visual pigments (cone opsins) with distinct peak spectral sensitivities, and provide convergent and divergent information to downstream neurons, which process differential input to discriminate color and provide high acuity vision. Photoreceptors display distinctive morphologies with specialized apical projections, the outer segments, which are highly modified nonmotile cilia [1]. Outer segments include membranous disks to increase surface area for containing

\footnotetext{
* Correspondence: dstenkam@uidaho.edu

Department of Biological Sciences, University of Idaho, 875 Perimeter Drive, MS 3051, Moscow, ID 83844-3051, USA
}

opsins and other phototransduction proteins, and photoreceptors maintain these outer segments with a high rate of protein synthesis, together with mechanisms for selective protein targeting and trafficking [2]. Rod photoreceptors in humans are particularly sensitive to genetic changes in structural and functional components; such defects cause hereditary retinal degenerations, which typically involve rod cell death, followed by cone cell death and loss of vision [3]. There is therefore great interest in increasing our depth of understanding of rod photoreceptor biology, health, the factors leading to cell death, and the discovery of strategies for promoting rod survival and/or rod replacement.

The zebrafish, an important animal model in vision research, is an example of a vertebrate with the endogenous capacity for rod replacement [4]. The zebrafish retina grows throughout its lifespan through the addition of new neurons at the retinal periphery, called the circumferential germinal zone (CGZ) or ciliary marginal zone (CMZ) [5-7]. In addition, Müller glia throughout 
the growing retina divide at a slow rate, generating a transiently-amplifying population of rod progenitors that migrate to the photoreceptor layer, and divide to generate rod photoreceptors [8]. The zebrafish retina therefore accumulates rods over its lifespan from these dedicated rod lineages. In zebrafish models of rod degeneration, either the most immediate precursors within the photoreceptor layer accelerate the production of new rods $[9,10]$, or the progenitor lineage is stimulated to increase rod neurogenesis to replace rods lost to damage [10]. In response to more widespread retinal damage due to chemical trauma, the progenitors generated by cell division of Müller glia gain the capacity to regenerate other types of retinal neurons [11-14], ultimately resulting in restoring visual function $[11,15]$. The existence of the rod lineage is well-documented in zebrafish $[8,16,17]$, and in other teleosts [18-20], and holds promise to inform the development of rod replacement strategies to treat human retinal disease. However, our knowledge of rods, and the rod lineage, within the zebrafish remains limited to a small number of rod-specific markers (primarily phototransduction components) [21], and a network of transcription factors important for rod determination and differentiation [5, 16, 22-25]. A single, distinctive marker for cells of the dedicated lineage that generates new rods, other than incorporation of Sphase markers, remains surprisingly elusive.

In the present study, we begin to fill this knowledge gap through RNA-sequencing (RNA-seq) analysis of the transcriptome of isolated rod photoreceptors, in comparison with non-rod retinal cells. In the transgenic line xops:eGFP, rod photoreceptors exclusively express high levels of GFP [26], permitting enrichment of rods from other retinal cells by fluorescence-activated cell sorting (FACS). This approach revealed transcripts that were upregulated in rods vs. other retinal cells, those that were present in rods but not differentially expressed, and those that were downregulated in rods vs. other retinal cells. Quantitative PCR (qPCR) studies suggested that this transcriptome is remarkably stable over the zebrafish lifespan from larval to adult ages, and appeared similar in rods that had regenerated following a chemical lesion. The zebrafish rod transcriptome is now a resource that can be mined for the identification of novel structural and functional components of rods, and possibly their progenitors, and for future comparative analyses with transcriptomes of rods and/or cones from key model organisms.

\section{Methods}

\section{Animals and tissue preparation}

All procedures involving animals were carried out in compliance with protocols approved by the University of Idaho Animal Care and Use Committee. Zebrafish
(Danio rerio) were maintained on a 14:10 light:dark cycle in recirculating, monitored system water, housed and propagated according to [27]. For this study we used the xops:eGFP transgenic line, in which the Xenopus rod opsin promoter drives expression of eGFP exclusively in rod photoreceptors [26], the gift of James Fadool, and a wild-type strain originally obtained from Scientific Hatcheries (now Aquatica Tropicals). In addition we used the xops:mCFP transgenic line, the gift of Ann Morris. In this line, the presence of $\mathrm{mCFP}$ in retinal rods leads to rapid rod degeneration, and a proliferative response to this degeneration by the rod precursor population [9].

To obtain retinal tissues for fluorescence-activated cell sorting (FACS), xops:eGFP fish were dark-adapted for 10-12 $\mathrm{h}$ to facilitate removal of retina from the RPE, anaesthetized with MS-222, and eyes enucleated with fine forceps. Corneas and lenses were removed, and retinas were peeled free from the RPE and whole eyecup in saline. In some cases, as indicated in Results, we used whole adult (1.5 yrs), juvenile (1 month), or larval (14 days post-fertilization; dpf) retinas for FACS and quantitative RT-PCR (qPCR). In all cases, animals were dark-adapted prior to retina removal, and in all cases, RNA isolation was performed immediately following tissue collection or FACS.

Tissues for in situ hybridization were fixed in phosphate-buffered, $4 \%$ paraformaldehyde containing 5\% sucrose for $1 \mathrm{~h}$ at room temperature, and washed in phosphate-buffered 5\% sucrose, and then a graded series ending in 20\% sucrose for overnight cyroprotection at $4{ }^{\circ} \mathrm{C}$. Tissues were embedded in a 1:2 solution of OCT embedding medium (Sakura Finetek) and phosphatebuffered, 20\% sucrose, and frozen in isobutane supercooled with liquid $\mathrm{N}_{2}$. After freezing solid, tissues were sectioned at $5 \mu \mathrm{m}$ on a Leica CM3050 cryostat $[15,28]$.

\section{Cell dissociation and FACS}

Whole retinas were dissociated into cell suspensions by incubating with $0.225 \%$ trypsin (Fisher ThermoScientific) and $0.001 \%$ papain (Worthington Biochemical) for $10 \mathrm{~min}$ at $37{ }^{\circ} \mathrm{C}$. Dissociation was stopped by the addition of heat-inactivated fetal bovine serum $(10 \% \mathrm{v} / \mathrm{v}$ final concentration). Suspended cells were pelleted and incubated with DNAseI at room temperature for $15 \mathrm{~min}$. Cells were pelleted and resuspended in $100 \mu \mathrm{L}$ phosphate-buffered ( $\mathrm{pH}$ 6.5) saline (PBS) and immediately FACS-sorted.

GFP+ vs. GFP- retinal cells were sorted using a BD FACSAria flow cytometer, using the $488 \mathrm{~nm}$ laser and FITC fluorescence filter, and the $70 \mu \mathrm{m}$ nozzle. Some cells were collected for fluorescence microscopy, or for post-sort FACS analysis. For RNA-seq or qPCR, GFP+ and GFP- cells were collected separately in the FACS sheath fluid, and RNA was immediately extracted. 
RNA isolation and quantitative real-time PCR (qPCR)

RNA was extracted from tissue samples using the NucleoSpin RNA kit (Macherey-Nagel) using the manufacturer's protocol, quantified and quality-checked on a Nanodrop spectrophotometer, and cDNA was synthesized using the SuperScript ${ }^{\circ}$ kit (New England Biotech) using random hexamer primers. Gene-specific primers used for qPCR were designed using AlleleID7/84 (Premier Biosoft), and are provided in Table 1. Amplification was carried out using a model 7900HT Fast Real-Time PCR System and SYBRGreen PCRMaster Mix (Applied Biosystems, Inc.). Relative quantitation of gene expression between GFP+ and GFPsamples was determined using the $2^{\wedge}-\Delta \Delta C t$ method with $18 \mathrm{~S}$ as the reference transcript [29], and five technical replicates per biological replicate. For samples from adult fish, retinal cells from a single adult fish constituted a biological replicate (3-5 replicates); for samples from juvenile fish, retinal cells from 10 to 15 juveniles were pooled for each biological replicate (3 replicates); for samples from larvae, retinal cells from 15 to 20 larvae were pooled for each biological replicate (3 replicates).

\section{Library construction, RNA-seq, and bioinformatics}

Both quantity and quality of RNA were assessed by using an Agilent 2100 Bioanalyzer. All samples used for RNAseq had an RNA integrity number (RIN) $>8.0$, and the experimental design retained pairing information between GFP+ cells and GFP- cells derived from both retinas of a single fish, allowing us to analyze them as paired samples. At least 5 ng of RNA was available per sample, and provided to the University of Idaho's Institute for Bioinformatics and Evolutionary Studies (IBEST) Genomics Core for RNA amplification, the generation of cDNA, sequencing, and bioinformatics. Quality and quantity of cDNA libraries were verified by Bioanalyzer. All sample preparation was achieved with Ovation ${ }^{\bullet}$ RNA-Seq System V2 (NuGEN), and sequencing performed on an Illumina (San Diego, CA) MiSeq with MiSeq Reagent Kit v3, 600 cycle kit. Four biological replicates (from four different fish) were sequenced (Fig. 1a). Reads were qualitytrimmed with Sickle (https://github.com/najoshi/sickle), and paired reads were overlapped with FLASH [30]. Overlapped reads were aligned against $\mathrm{Zv} 9.75$ using the Burrows-Wheeler aligner [31]. BAM files were sorted with using SAMtools [32], and reads were counted by feature using HTSeq-count [33]. Counts were analyzed and differentially expressed genes were identified with $R$ [34] and edgeR [35]. Descriptive plots were generated, and gene ontology (GO) analysis and hierarchical clustering were performed, with $\mathrm{R}$ and GOstats [36]. Comparison with a publicly available microarray dataset [37] was done using paralogue and probe identifier information available via Ensembl's BioMart (http://uswest.ensembl.org/biomart/ martview/83d09c7c5ff71f36d9df58ed9f566c78).

\section{Probe preparation and in situ hybridization}

Zebrafish rho (rhodopsin) cDNA, in pBK-CMV phagemid, was the gift of $\mathrm{T}$. Vihtelic. Other cDNAs were generated as follows. Total RNA was extracted from homogenized adult zebrafish retina, and cDNA was generated using random hexamers and oligo(dT) primers. Gene-specific primers (Table 2) corresponding to rhol, dscamb, rxrga, and $r x r g b$ predicted mRNAs were designed using PrimerBLAST (https://www.ncbi.nlm.nih.gov/tools/primer-blast/), were used for PCR amplifications, and the resulting amplicons were gel-purified and ligated using TA-ligation into the pGEM-T-Easy vector (Promega), which contains T7 and SP6 promoters. cDNAs were sequence-verified (ElimBio; St. Hayward, CA), with sequencing results compared to original genomic sequence using nucleotide Blast software and viewed in Sequencher (GeneCodes). Digoxigenin (dig) -labeled cRNA probes were prepared using T7 or SP6 RNA polymerase (Roche) according to the manufacturer's instructions. In situ hybridization was carried out according to Nelson et al. [16]. In brief, sections were rehydrated, permeabilized with proteinase $\mathrm{K}$, dehydrated and incubated with probe in a solution containing $50 \%$ formamide, with hybridization temperatures optimized for each probe using PolyPro [38]. Hybridized tissues were treated with RNAse $\mathrm{A}$, and the presence of dig was detected with anti-dig antibodies conjugated to alkaline phosphatase, followed by an NBT-BCIP (Roche) or BM-purple (Sigma) color reaction carried out according to the manufacturer's instructions. In situs were imaged on a Leica DM2500 upright microscope with a Leica DFC700T camera using DIC optics. In addition to antisense probes, sense probes were also prepared and confirmed not to generate detectable signal.

\section{Retinal damage and regeneration}

The retinas of adult xops:eGFP fish (1 yr) were chemically lesioned to destroy all retinal neurons while sparing Müller glia [13]. Briefly, fish were anaesthetized by tricaine and an incision was made across the cornea with a sapphire blade. Using a Hamilton syringe, $0.4 \mu \mathrm{L}-0.6 \mu \mathrm{L}$ of $200 \mu \mathrm{M}$ ouabain was injected into the vitreal chamber of the right eye, resulting in an estimated intraocular concentration of $10 \mu \mathrm{M}[11,15,39]$. Loss of GFP+ photoreceptors was verified in sectioned retinas obtained from parallel experiments at 3 days post-injury ( $3 \mathrm{dpi}$ ), and by viewing retinas of live, anaesthetized fish with epifluorescence stereomicroscopy (Leica M165 FC), also at 3 dpi. Lesioned zebrafish were allowed to recover, and regenerate their retinas [11] until $14 \mathrm{dpi}$ or $30 \mathrm{dpi}$, and were humanely sacrificed to collect retinas for cell dissociation, FACS, and qPCR, or to collect whole eyes for cryosectioning.

\section{Indirect immunofluorescence and confocal microscopy}

Histological processing and sectioning was carried out as previously described [28]. In brief, whole eyes were 
Table 1 Primers used for qPCR

\begin{tabular}{|c|c|c|}
\hline Gene & Sense Primer $5^{\prime}->3^{\prime}$ & Anti-sense Primer 5'- > 3' \\
\hline aipl1 & TCCAGTCAGTCTITACAC & CCTTAGTTCCAGTCACAA \\
\hline ajap1 & GGAGTAAGGTGTCTAACT & TTCCTGATATTCGTCCAT \\
\hline apoc1l & CCCAATTACCTTGTGTTT & ACAGTGTGACTTTGTATTG \\
\hline atat1 & CTAATGTGAATCTGCTATA & ACTCAAGTTACTATCCAA \\
\hline bbs4 & ACCACATTAGGACTGCTG & TCATAGGTCAGAGCGTTTC \\
\hline cabp4 & AGTTCGTTATGATGTTGTCTCT & CTATGATGATCCGCCACTG \\
\hline cobl & TCTAACCATACAGCAGAATCCA & GTCCAGGCGACAACATTG \\
\hline cry3 & TTACTCTTCTGGATTCC & ATATAAACACACCGTACA \\
\hline dscamb & AAGAAGATGGTCTGACTC & CAAGGGAAAGCAAGTATT \\
\hline egf & TAAGTGAGTGGACAATGTT & GTCTTCGTGTTCCATCTA \\
\hline enc1 & ACGAGTCAGTATATTTCT & GTAAGTAACGAGCCTATA \\
\hline esrrb & CGTCTCCTCATACTTCAG & TCCTCCACTCTATTAGCA \\
\hline esrrd & CATGACCTTATGTGACCTT & CAGAAACCTGGTATGTGT \\
\hline gc2 & CTGTGTTAATTGGTGGAA & AGAGTATCGTAGGACATAA \\
\hline gc3 & CTCTATTCACTGCCATAT & CATGGTTACTGTTAAGAC \\
\hline gngt1 & AATCCATTCATTCAACACAACAT & ACTTCCATCTTCGCCTTATC \\
\hline gucyzf & TAGCATTACACTATGGATT & GCCTATGATTCCTACTIT \\
\hline kcnv2a & GCAGGAGTTAAGTAAGGATAT & TAGGAGTGGAGAACAGTC \\
\hline kita & AATAAGCTTGCCGCCACCATGGAATATCACTGCGTTCT & CAAATATTTGTAGGTGAGCACAATCAGGATGAGAAC \\
\hline lingola & TGCTTGTACGGATTGAAT & ATGTTGAGGAAACGAAGA \\
\hline Lplastin & GCAGTGGGTGAACGAAACAC & TCGAGATCGCATACTTGGCG \\
\hline mef2ca & TGTAATCATTCAGCGTAGTG & TCTAAGGTGTGCCGTTAT \\
\hline mef2cb & CCCGTGAATAACCAGATC & GTGACATGCTGTTTCTT \\
\hline mpeg1.1 & CGGGTTCAAGTCCGTAACCA & TGGCGTCAGCGATTTCTTCT \\
\hline msi1 & CGAGCCCAGCCTAAGTTG & ATCTTCAATAGTCGTGTTCACTGA \\
\hline ncam1b & AGTTTGATAAAGATGTTCGTTTC & TTAATGCTGCGGAAGTCA \\
\hline ngf & GAGAAGACTACAAGCGAAT & CGACAACAATAAGGAGGAT \\
\hline $\mathrm{nr} 1 \mathrm{~d} 4 \mathrm{a}$ & AATCATCTTATCGCACAAC & ATAGTAGTAGGTAGTAGGAGTA \\
\hline$n r 1 d 4 b$ & AACGGTCACTATAACTTC & GAATAGCTGTTGTGTTTAG \\
\hline $\mathrm{nr} 2 \mathrm{f} 1 \mathrm{~b}$ & TGAGAAGAACACAGAGTAA & AGGATTGCTGACTATAACA \\
\hline $\mathrm{nrl}$ & GATGGTCAGAGGAGAATG & GGTTGTAACGAGTGCTTA \\
\hline nucb2b & ATGATATGGTGGAGATGGA & CTTGTTCGTGGCAGTAAT \\
\hline panx $1 b$ & GCAGAGTGATTCTAAGTA & GAGTGAGATGAGTAACAA \\
\hline pdca & TGCCGATGTGGAATAATCAGA & ACAGCGTCATTACTCATTCTATCT \\
\hline ppdpfa & TAGCGTTTACCCGACCAA & TTCCCCGTCCTCTAAAG \\
\hline prom1b & CAGTTGGAGTGACAGTTG & TCAGGTCTCTTATGTTGGT \\
\hline $\operatorname{rtn} 2 a$ & GGACACATAGACACAGACAA & CCTTCCAGTAGACCAGGT \\
\hline rho & ACTTCCGTTTCGGGGAGAAC & GAAGGACTCGTTGTTGACAC \\
\hline rhol & GCTGTGAGATGCTGGATT & GTTGTTGTTGTTGTTGTTGTC \\
\hline rims3 & AGAGGAGGTCAGTTAGAG & TATATGTTGCTGGAATGTTC \\
\hline rxrga & TTCACACTGGTCATTCAA & AAGGCATTATAGAGCGATT \\
\hline rxrgb & ACATAATACAGACAGAGACT & TAATAGCACAAGACAGAATC \\
\hline thrb & TCTGGTCTGATGAGTCTA & GTATTAGCCTGGTGATGA \\
\hline tprn & CAAACAACAAACATATAATCAAGT & TCTGAATGGTCGTGAATG \\
\hline
\end{tabular}


Table 1 Primers used for qPCR (Continued)

\begin{tabular}{lll}
\hline Gene & Sense Primer $5^{\prime}->3^{\prime}$ & Anti-sense Primer $5^{\prime}->3^{\prime}$ \\
\hline tulp1b & CAAGGAATCAACAGAGAAG & CATCATCATCATCGTCATC \\
sept8b & CTATCGTGGACTACATTGA & ATGAAGTACAGGCAGATG \\
znf536 & CAATGGACAGAATTAGGAATCA & CACAAAGAGGACAGGGATAT \\
GS & GAACGCCACTTGTCCCTCTA & GTTGGTGAGCGATTGTCT \\
\hline
\end{tabular}

perforated at the cornea, to create a slit through which lenses were removed. Eyecups were immersed in phosphate-buffered ( $\mathrm{pH}-7.4), 4 \%$ paraformaldehyde containing 5\% sucrose and fixed at room temperature for $1 \mathrm{~h}$. Eyes were subjected to sequential washes with increasing concentrations of phosphate-buffered sucrose, and cryoprotected overnight at $4{ }^{\circ} \mathrm{C}$ in phosphate-buffered, $20 \%$ sucrose. Eyes were embedded in a 1:2 mixture of OCT (optimal cutting temperature; Sakura Finetek) and buffered, 20\% sucrose, and sectioned on a Leica CM3050 cryostat at $5 \mu \mathrm{m}$. Sections were blocked in $20 \%$ goat serum $1 \mathrm{~h}$, room temperature, and then incubated with primary antibody 1D1 (1:20) (the gift of James Fadool) overnight, $4{ }^{\circ} \mathrm{C}$, which stains zebrafish rhodopsin [40]. Sections were washed with phosphate-buffered ( $\mathrm{pH}-7.4)$ saline containing $0.01 \%$ TritonX-100 (PBST), and then incubated with secondary antibody conjugated to Cy3 (1:200; Jackson Immunoresearch) for $2 \mathrm{~h}$ at room temperature. Mounted sections were imaged with a Nikon Andor spinning disk confocal microscope and Zyla sCMOS camera using 40X dry and 60X oil immersion objectives.

\section{Results}

Transcripts of rods of adult zebrafish retina

We isolated highly pure rod and non-rod retinal cell populations by FACS-sorting cell suspensions from adult xops:eGFP zebrafish retinas (Fig. 1a). GFP+ cells (P1 in Fig. 1b) made up $10-20 \%$ of all collected retinal cells and constituted a distinctive cell population as compared
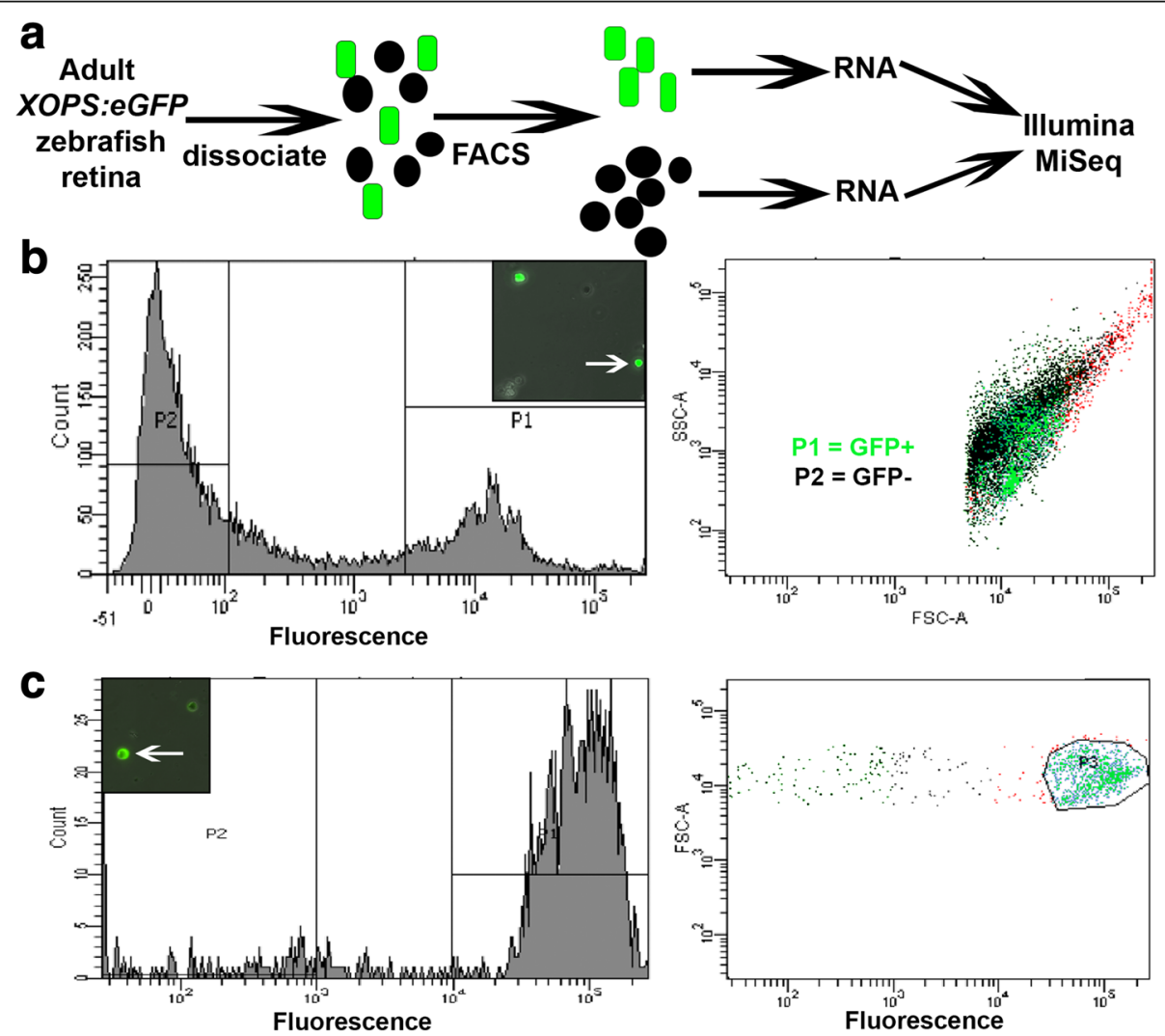

Fig. 1 Dissociation, FACS separation, and RNA-seq analysis of GFP+ rod photoreceptors and GFP- retinal cells. a Experimental procedure. b Representative FACS results showing dissociated cells (inset; arrow indicates GFP+ cell), GFP+ population collected in P1, GFP- population collected in P2. Cells not in P1 or P2 are in red in the second panel. c Post-sort analysis of a sorted GFP+ population by fluorescence microscopy (inset; arrow indicates GFP+ cell) and FACS. SSC, side scatter (reflecting object complexity); FSC, forward scatter (reflecting object size) 
Table 2 Primers used for generation of in situ probes

\begin{tabular}{lll}
\hline Primer name & Primer sequence 5'- > 3' & Probe length \\
\hline rhol_probe_F & CGAAGTGACCCGAATGGTGA & $764 \mathrm{~b}$ \\
rhol_probe_R & GCGGAATGAACCGCCTTAAC & \\
dscamb_probe_F & TCTGGATCCCCGGAGACAAT & $757 \mathrm{~b}$ \\
dscamb_probe_R & TCTGGATCCCCGGAGACAAT & \\
rxrga_probe_F & GGAGAAGATCCTGGACGCTG & $734 \mathrm{~b}$ \\
rxrga_probe_R & AGTGTGCGCTGGGGTTATT & \\
rxrgb_probe_F & CGCGGAATGGATACTCACGA & $807 \mathrm{~b}$ \\
rxrgb_probe_R & TCCGCTGCATGGCAGATATT & \\
\hline
\end{tabular}

with the GFP- population (P2 in Fig. 1b). Visualization of samples using epifluorescence microscopy suggested that the majority of dissociated GFP+ profiles, and FACS-sorted GFP profiles, appeared to be rounded-up rod cell bodies rather than outer segments or other fragments (insets in Fig. 1b, c). To verify enrichment of our sorted populations, a separate sample from one fish was used to collect GFP+ cells using the same FACS-sorting parameters as those used for RNA-seq, and we subsequently examined the sorted population by fluorescence microscopy and by post-sort analysis (Fig. 1c). These results indicated that P1 population was highly enriched for GFP+ cells (Fig. 1c), and therefore suitable for transcriptome analysis.

We performed RNA-seq on both the rod (GFP+; P1) and the "non-rod" (GFP-; P2) populations, in order to identify transcripts enriched, present, or depleted in the rod population as compared with other retinal cells (similar to the approach of [41]). The resulting dataset is publicly available via the Gene Expression Omnibus (GEO; accession \# GSE100062). Sequencing depth ranged from 2,781,516 to 3,480,515 reads per sample, and mapping percentages ranged from $97.0 \%$ to $97.4 \%$ per sample. Multidimensional scaling showed good separation of GFP+ vs. GFP- samples along the first dimension and separation by sample along the second dimension (Additional file 1: Figure S1A). A plot of estimated Biological Coefficient of Variation (BCV) indicated a trend in dispersion associated with expression (Additional file 1: Figure S1B), leading us to fit a trended model within edgeR before doing differential expression analysis. Differentially expressed transcripts were identified as those significantly upregulated or downregulated in the GFP+ population vs. the GFP- population. Those identified with a false discovery rate (FDR) of $<0.01$ consisted of 1629 distinct entries (597 upregulated, 1032 downregulated); those identified with an FDR of $<0.05$ consisted of 2439 entries (Additional file 1: Figure S1C). The top 50 upregulated and top 50 downregulated transcripts within the GFP+ vs. GFP- populations, based upon FDR, are provided as Tables 3 and 4, respectively.
Numerous transcripts known to be expressed exclusively by rods were significantly upregulated (enriched) in the GFP+ cell population, including rho, pde6g, rom $1 b$, and gnat1 (Table 3). Numerous transcripts known to be primarily expressed by other retinal cell types were significantly downregulated (depleted) in the GFP+ cell population, including cone transcripts opn1lw2 (long wavelength-sensitive cone opsin 2), opn1mw3 (cone opsin rh2-3), and cnga3a, and the macrophage/microglial marker mpeg1 [42] (Table 4). These outcomes further corroborated the rod (GFP+) vs. non-rod (GFP-) identities of our sample cell populations.

To provide broad classification of rod-enriched transcripts, we used gene ontology (GO) analysis. GO molecular function categories significantly overrepresented in GFP+ samples included those related to cyclic nucleotide metabolism, intermediary metabolism, and ion transport (Fig. 2a), and GO biological processes that were overrepresented included intracellular transport processes, photoreceptor cell development, and the kit and notch signaling pathways (Fig. 2b). GO biological process categories related to cell stress or apoptosis were not overrepresented, suggesting that, although the GFP+ rods did not maintain their morphologies during the dissociation and sorting procedures (insets in Fig. 1a, b), these procedures likely did not cause differential upregulation of genes related to stress and cell death in the rods. These findings are consistent with the recent report by Richardson et al. [43] showing that FACS does not perturb gene expression. GO cellular component categories significantly overrepresented in the GFP+ samples included those related to cytoskeletal components and those related to cilia (Fig. 2c). These categories reflect the underlying structure, function, and very likely the ongoing developmental programs engaged for maintaining rod structure and function. It was surprising, however, that some of these categories were overrepresented considering the large number of cones likely to be present in the GFP- retinal cell population that were also expected to demonstrate similar molecular functions, biological processes, and cellular components. Hierarchical clustering of the rod-enriched transcripts returned only three, highly similar clusters (Fig. 2d), suggesting very little sample heterogeneity within the GFP+ samples and within the GFP-samples. Our experimental design included sex as a potential biological variable, such that we could analyze a sex X rod interaction. This analysis returned only five entries with an FDR $<0.05$ (Table 5).

The analyses described above focused upon transcripts that were differentially expressed in GFP+ vs. GFP- cells, therefore identifying enriched transcripts in either population. To identify additional transcripts present in rods, but not necessarily enriched in comparison with other 
Table 3 Top 50 transcripts significantly upregulated (enriched) in GFP+ (rods) vs GFP- retinal cell populations

\begin{tabular}{|c|c|}
\hline Name & Description \\
\hline$\overline{g c 2}$ & $\begin{array}{l}\text { guanylyl cyclase } 2 \\
\text { [Source:ZFIN;Acc: } \\
\text { ZDB-GENE-011128-8] }\end{array}$ \\
\hline esrrd & $\begin{array}{l}\text { estrogen-related } \\
\text { receptor delta [Source: } \\
\text { ZFIN;Acc:ZDB-GENE-040616-3] }\end{array}$ \\
\hline zgc:112,334 & $\begin{array}{l}\text { zgc:112,334 [Source: } \\
\text { ZFIN;Acc: } \\
\text { ZDB-GENE-050809-120] }\end{array}$ \\
\hline gngt1 & $\begin{array}{l}\text { guanine nucleotide } \\
\text { binding protein } \\
\text { (G protein), gamma } \\
\text { transducing activity } \\
\text { polypeptide } 1 \\
\text { [Source:ZFIN; } \\
\text { Acc:ZDB-GENE-030131-7596] }\end{array}$ \\
\hline arhgap29a & $\begin{array}{l}\text { Rho GTPase activating } \\
\text { protein 29a [Source:ZFIN;Acc: } \\
\text { ZDB-GENE-030131-9510] }\end{array}$ \\
\hline kitb & $\begin{array}{l}\text { kit receptor b [Source: } \\
\text { ZFIN;Acc:ZDB-GENE-050916-2] }\end{array}$ \\
\hline si:dkey-204f11.59 & $\begin{array}{l}\text { si:dkey-204f11.59 } \\
\text { [Source:ZFIN; } \\
\text { Acc:ZDB-GENE-040724-220] }\end{array}$ \\
\hline ajap1 & $\begin{array}{l}\text { adherens junctions } \\
\text { associated protein } 1 \\
\text { [Source:ZFIN; } \\
\text { Acc:ZDB-GENE-041210-353] }\end{array}$ \\
\hline OSBPL1A (2 of 2) & $\begin{array}{l}\text { oxysterol binding } \\
\text { protein-like 1A } \\
\text { [Source:HGNC } \\
\text { Symbol;Acc:16,398] }\end{array}$ \\
\hline pde6g & $\begin{array}{l}\text { phosphodiesterase } \\
6 G \text {, cGMP-specific, } \\
\text { rod, gamma } \\
\text { [Source:ZFIN; } \\
\text { Acc:ZDB-GENE-030904-1] }\end{array}$ \\
\hline
\end{tabular}

$\begin{array}{ll}\text { UBAP1L (1 of 2) } & \text { ubiquitin associated } \\ & \text { protein 1-like [Source: } \\ & \text { HGNC Symbol;Acc:40,028] } \\ \text { rcvrna } & \text { recoverin a [Source: } \\ & \text { ZFIN;Acc: } \\ & \text { ZDB-GENE-050913-106] } \\ & \text { retinal outer segment } \\ & \text { membrane protein } \\ & \text { 1b [Source:ZFIN;Acc: } \\ & \text { ZDB-GENE-040426-1073] }\end{array}$

rorb RAR-related orphan

tmtops2a

cerkl

cobl

hen3

(mouse) [Source:ZFIN; receptor $\mathrm{B}$ [Source:ZFIN Acc:ZDB-GENE-061204-2]

teleost multiple tissue opsin 2a [Source:

ZFIN:Acc:

ZDB-GENE-130129-3]

ceramide kinase-like

[Source:ZFIN;

Acc:ZDB-GENE-070410-38]

$\begin{array}{ll}\log F C & \text { FDR } \\ 3.032892 & 5.22 \mathrm{E}-22\end{array}$

$\begin{array}{ll}3.642435 & 8.52 \mathrm{E}-17 \\ 3.829432 & 3.64 \mathrm{E}-16 \\ 2.959265 & 4.60 \mathrm{E}-16 \\ & \\ & \\ & \end{array}$

$2.782837 \quad 1.06 \mathrm{E}-15 \quad$ rom $1 \mathrm{a}$

$3.212857 \quad 2.27 \mathrm{E}-15$

kenv2a

$2.499397 \quad 7.05 E-15$

ratho

$2.427894 \quad 7.09 \mathrm{E}-15 \quad \mathrm{cpl} \times 4 \mathrm{C}$

samd 11

$3.045885 \quad 9.01 E-15$

BX248120.1

$2.868683 \quad 9.01 \mathrm{E}-15$

$2.719941 \quad 5.43 \mathrm{E}-14$

arhgef10lb

$2.85896 \quad 5.78 \mathrm{E}-14$

guca1a

$2.48207 \quad 6.19 \mathrm{E}-14$

si:dkeyp-41f9.3

$2.265541 \quad 1.05 \mathrm{E}-13$

TDRD7B

$2.181324 \quad 1.11 \mathrm{E}-13$

cordon-bleu homolog

Acc:ZDB-GENE-091020-11]

hyperpolarization activated

cyclic nucleotide-gated

potassium channel 3

[Source:ZFIN;

Acc:ZDB-GENE-060503-193]

$\mathrm{PLCH} 2$ (1 of 2 )

$2.417617 \quad 1.19 \mathrm{E}-13$

cabp4

guca1b
Table 3 Top 50 transcripts significantly upregulated (enriched) in GFP+ (rods) vs GFP- retinal cell populations (Continued)

\begin{tabular}{llll} 
Name & Description & $\log F C$ & FDR \\
\hline zgc:162,144 & zgc:162,144 [Source: & 2.775518 & $1.70 \mathrm{E}-13$ \\
& ZFIN;Acc: & & \\
& ZDB-GENE-030131-7630] & & \\
& & & \\
& guanine nucleotide & &
\end{tabular}

guanine nucleotide

$70 \mathrm{E}-13$

binding protein

(G protein), beta polypeptide

$1 b$ [Source:ZFIN;ACC

:ZDB-GENE-040426-2855]

unc-119 homolog 2

2.116224

$1.79 \mathrm{E}-13$

[Source:ZFIN;

Acc:ZDB-GENE-030131-7635]

protein tyrosine

phosphatase domain

containing 1

[Source:HGNC Symbol;

Acc:30,184]

phosducin a [Source:

ZFIN;ACC:

ZDB-GENE-031023-1]

retinal outer segment

membrane protein $1 \mathrm{a}$

[Source:ZFIN;

Acc:ZDB-GENE-040426-1765]

potassium channel, subfamily $\mathrm{V}$, member

2a [Source:ZFIN;

Acc:ZDB-GENE-091117-27]

rhodopsin [Source:ZFIN

Acc:ZDB-GENE-990415-271]

complexin 4c [Source:ZFIN

Acc:ZDB-GENE-101018-1]

sterile alpha motif domain

containing 11 [Source:ZFIN;

Acc:ZDB-GENE-060428-2]

Uncharacterized protein

[Source:UniProtKB/TrEMBL;

Acc:E7F755]

S-antigen; retina and pineal gland (arrestin) a

[Source:ZFIN;

Acc:ZDB-GENE-040426-1538]

Rho guanine nucleotide exchange factor (GEF)

10-like b [Source:ZFIN;Acc:

ZDB-GENE-090313-222]

guanylate cyclase activator

1A [Source:ZFIN;

Acc:ZDB-GENE-011128-5]

si:dkeyp-41f9.3

.253732

$2.91 \mathrm{E}-13$

2.797727

3.06E-13

$3.176656 \quad 3.68 \mathrm{E}-13$

$2.625431 \quad 4.38 \mathrm{E}-13$

3.214731

4.63E-13

$2.863052 \quad 7.98 \mathrm{E}-13$

$2.708617 \quad 9.40 \mathrm{E}-13$

2.586515

1.34E-12

Source:ZFIN

Acc:ZDB-GENE-091118-56]

Tudor domain-containing

protein 7B

SSource:

UniProtKB/Swiss-Prot;

Acc:E7FDW8]

phospholipase C, eta 2

[Source:HGNC Symbol;

Acc:29,037]

calcium binding protein 4

[Source:ZFIN

Acc:ZDB-GENE-081 104-291]

$3.089512 \quad 1.44 \mathrm{E}-12$

$2.476543 \quad 160 \mathrm{E}-12$

$2.765826 \quad 1.68 \mathrm{E}-12$

$2.849587 \quad 1.72 \mathrm{E}-12$

$2.840789 \quad 2.06 \mathrm{E}-12$ activator $1 \mathrm{~B}$ 
Table 3 Top 50 transcripts significantly upregulated (enriched) in GFP+ (rods) vs GFP- retinal cell populations (Continued)

\begin{tabular}{|c|c|c|c|}
\hline Name & Description & $\log \mathrm{FC}$ & FDR \\
\hline & $\begin{array}{l}\text { [Source:ZFIN; } \\
\text { Acc:ZDB-GENE-011128-6] }\end{array}$ & & \\
\hline grk1a & $\begin{array}{l}\text { G protein-coupled receptor } \\
\text { kinase } 1 \mathrm{a} \\
\text { [Source:ZFIN; } \\
\text { Acc:ZDB-GENE-050823-1] }\end{array}$ & 2.930581 & 1.10E-11 \\
\hline gnb1a & $\begin{array}{l}\text { guanine nucleotide } \\
\text { binding protein } \\
\text { (G protein), beta } \\
\text { polypeptide 1a } \\
\text { [Source:ZFIN; } \\
\text { Acc: } \\
\text { ZDB-GENE-030131-823] }\end{array}$ & 2.886447 & 1.19E-11 \\
\hline slc6a15 & $\begin{array}{l}\text { solute carrier family } \\
6 \text { (neutral amino } \\
\text { acid transporter), } \\
\text { member } 15 \\
\text { [Source:ZFIN; } \\
\text { Acc:ZDB-GENE-050420-93] }\end{array}$ & 2.779643 & 1.45E-11 \\
\hline ppdpfa & $\begin{array}{l}\text { pancreatic progenitor } \\
\text { cell differentiation } \\
\text { and proliferation } \\
\text { factor a [Source:ZFIN; } \\
\text { Acc:ZDB-GENE-030219-204] }\end{array}$ & 2.669857 & $1.71 \mathrm{E}-11$ \\
\hline pde6b & $\begin{array}{l}\text { phosphodiesterase 6B, } \\
\text { cGMP-specific, rod, } \\
\text { beta [Source:ZFIN; } \\
\text { Acc:ZDB-GENE-090421-2] }\end{array}$ & 3.049742 & $2.01 \mathrm{E}-11$ \\
\hline znf536 & $\begin{array}{l}\text { zinc finger protein } 536 \\
\text { [Source:ZFIN; } \\
\text { Acc:ZDB-GENE-030616-624] }\end{array}$ & 2.683055 & 2.19E-11 \\
\hline SUSD3 & $\begin{array}{l}\text { sushi domain containing } \\
3 \text { [Source:HGNC } \\
\text { Symbol;Acc:28,391] }\end{array}$ & 2.124055 & $2.28 \mathrm{E}-11$ \\
\hline gnat1 & $\begin{array}{l}\text { guanine nucleotide } \\
\text { binding protein (G protein), } \\
\text { alpha transducing } \\
\text { activity polypeptide } 1 \\
\text { Source:ZFIN; } \\
\text { Acc:ZDB-GENE-011128-11] }\end{array}$ & 2.967409 & $3.45 \mathrm{E}-11$ \\
\hline sagb & $\begin{array}{l}\text { S-antigen; retina and } \\
\text { pineal gland (arrestin) b } \\
\text { [Source:ZFIN; } \\
\text { Acc:ZDB-GENE-050913-98] }\end{array}$ & 3.155676 & $3.69 \mathrm{E}-11$ \\
\hline asmt & $\begin{array}{l}\text { acetylserotonin } \\
\text { O-methyltransferase } \\
\text { [Source:ZFIN; } \\
\text { Acc:ZDB-GENE-080220-43] }\end{array}$ & 1.844975 & 4.41E-11 \\
\hline pfkfb4l & $\begin{array}{l}\text { 6-phosphofructo } \\
\text {-2-kinase/fructose-2,6- } \\
\text { biphosphatase 4, like } \\
\text { [Source:ZFIN; } \\
\text { Acc:ZDB-GENE-031031-4] }\end{array}$ & 1.93027 & 4.63E-11 \\
\hline alpl & $\begin{array}{l}\text { alkaline phosphatase, } \\
\text { liver/bone/kidney } \\
\text { [Source:ZFIN; } \\
\text { Acc:ZDB-GENE-040420-1] }\end{array}$ & 2.701265 & $5.22 \mathrm{E}-11$ \\
\hline slc24a1 & $\begin{array}{l}\text { solute carrier family } 24 \\
\text { (sodium/potassium/calcium } \\
\text { exchanger), member } 1 \\
\text { [Source:ZFIN; } \\
\text { Acc:ZDB-GENE-060503-191] }\end{array}$ & 2.88482 & 7.45E-11 \\
\hline
\end{tabular}

retinal cells, we generated a list of transcripts for which all GFP+ samples returned a non-zero value. This list of transcripts present in rods amounted to 13,324 distinct entries (not shown), approximately $23 \%$ of the total number of predicted transcripts $(58,549$; Ensembl GRCz10) encoded by the zebrafish genome. This list included numerous photoreceptor (but not rod-specific) genes such as irbp, neurod, crx, and $r x 1$, and some genes not previously known to be expressed in rod photoreceptors, such as opsin 4.1, a zebrafish melanopsin [44], and several nuclear hormone receptor genes including rxrga. The latter is noteworthy because the mouse orthologue $(R X R \gamma)$ was reported to be cone-specific [45].

Forty-five transcripts were selected for validation analysis by qPCR in independently sorted GFP+ vs. GFP- cells from adult xops:eGFP zebrafish. Transcripts were prioritized for validation based upon predicted or know functions as transcription factors (e.g. esrrb, $n r l, n r 2 f 1 b, r \times r g a$ ), as components of cell signaling pathways (e.g. ngf, kita), or as cell adhesion molecules (e.g. dscamb, ncam1b), because future analysis of such components stands to reveal new insights into regulation of rod development, maturation, and/or maintainance. We also selected some transcripts known to have structural (e.g. prom1b, bbs4) or functional requirements in photoreceptors (e.g. rhol, gngt1, pdca). Finally, we selected transcripts that were detected as enriched in rods, as well as some that were detected as present in rods, but not enriched, to more thoroughly validate the RNA-seq dataset.

Selected transcripts that were detected by RNA-seq as significantly enriched in rods, were all determined to be significantly enriched in rods by qPCR, at similar relative magnitudes (Fig. 3a). Selected transcripts that were detected by RNA-seq as present, though not enriched in rods, were all detectable by qPCR (see first five genes in Fig. $3 b)$. Some of these were detected by qPCR to be significantly enriched (the first three genes in Fig. 3b), a minor discrepancy perhaps related to the larger number of biological replicates used for qPCR. Transcripts detected by RNA-seq as significantly depleted but still present in rods, were nearly all determined to be significantly depleted in rods by qPCR, with the exception of $m e f 2 c b$, where qPCR did not detect a significant difference (see last six genes in Fig. 3b), but nevertheless detected the presence of this transcript in rods. These qPCR results provide strong validation that the RNA-seq dataset generated in this study will serve as a reliable resource for many future applications.

\section{Rod photoreceptor transcripts over the lifespan and in a genetic model for rod degeneration}

As zebrafish grow, they continue to generate new rods throughout the retina from a dedicated rod lineage [4, 16], the apex of which (stem cell for rod lineage) has been identified as the Müller glial cell [8]. Therefore we wished to determine whether the rod transcriptome remained consistent over the zebrafish lifespan, or if the 
Table 4 Top 50 transcripts significantly downregulated (depleted) in GFP+ (rods) vs GFP- retinal cell populations

\begin{tabular}{|c|c|c|c|}
\hline Name & Description & $\log \mathrm{FC}$ & FDR \\
\hline si:dkey-27i16.2 & si:dkey-27i16.2 [Source:ZFIN;Acc:ZDB-GENE-030131-9667] & -6.03866537 & $1.88 \mathrm{E}-38$ \\
\hline ptpre & protein tyrosine phosphatase, receptor type, C [Source:ZFIN;Acc:ZDB-GENE-050208-585] & -6.06476722 & $3.46 \mathrm{E}-31$ \\
\hline apoc11 & apolipoprotein C-I like [Source:ZFIN;Acc:ZDB-GENE-030131-1074] & -4.46320866 & 2.75E-30 \\
\hline cd74a & CD74 molecule, major histocompatibility complex, class II invariant chain a [Source:ZFIN;Acc:ZDB-GENE-000901-1] & -4.67633439 & 1.65E-28 \\
\hline bzw1b & basic leucine zipper and W2 domains 1b [Source:ZFIN;Acc:ZDB-GENE-040426-2881] & -3.66358803 & $9.06 \mathrm{E}-28$ \\
\hline si:dkey-2501.6 & si:dkey-25o1.6 [Source:ZFIN;Acc:ZDB-GENE-091204-276] & -5.26240739 & 3.27E-27 \\
\hline si:ch211-260d11.1 & si:ch211-260d11.1 [Source:ZFIN;Acc:ZDB-GENE-091204-40] & -6.02459793 & $1.05 E-26$ \\
\hline lgals3bpb & lectin, galactoside-binding, soluble, 3 binding protein b [Source:ZFIN;Acc:ZDB-GENE-040426-2262] & -5.09075533 & $1.25 \mathrm{E}-26$ \\
\hline corola & coronin, actin binding protein, 1A [Source:ZFIN;Acc:ZDB-GENE-030131-9512] & -7.62303025 & $1.06 \mathrm{E}-25$ \\
\hline hbaa1 & hemoglobin alpha adult-1 [Source:ZFIN;Acc:ZDB-GENE-980526-79] & -9.74873113 & $1.70 \mathrm{E}-25$ \\
\hline si:dkey-25o1.5 & si:dkey-2501.5 [Source:ZFIN;Acc:ZDB-GENE-091204-344] & -9.53659867 & $7.14 \mathrm{E}-23$ \\
\hline sla2 & Src-like-adaptor 2 [Source:ZFIN;Acc:ZDB-GENE-080204-98] & -9.56172956 & $2.35 \mathrm{E}-22$ \\
\hline inpp5d & inositol polyphosphate-5-phosphatase D [Source:ZFIN;Acc:ZDB-GENE-100922-30] & -4.44994274 & 1.17E-21 \\
\hline mpeg1 & macrophage expressed 1 [Source:ZFIN;Acc:ZDB-GENE-030131-7347] & -9.35334321 & 2.15E-21 \\
\hline ZFP36 & ZFP36 ring finger protein [Source:HGNC Symbol;Acc:12,862] & -5.4525006 & $1.53 \mathrm{E}-20$ \\
\hline ankrd33ab & ankyrin repeat domain 33Ab [Source:ZFIN;Acc:ZDB-GENE-100729-1] & -3.13603996 & $1.97 \mathrm{E}-20$ \\
\hline pfn1 & profilin 1 [Source:ZFIN;Acc:ZDB-GENE-031002-33] & -4.86406116 & $2.72 \mathrm{E}-20$ \\
\hline grk7a & G-protein-coupled receptor kinase 7a [Source:ZFIN;Acc:ZDB-GENE-050824-1] & -2.77617205 & 5.07E-20 \\
\hline rev1 & recoverin [Source:ZFIN;Acc:ZDB-GENE-030131-7590] & -2.80718642 & 2.57E-19 \\
\hline tagapa & T-cell activation RhoGTPase activating protein a [Source:ZFIN;Acc:ZDB-GENE-040426-1877] & -6.39333701 & $1.05 E-18$ \\
\hline si:dkey-126 g1.9 & si:dkey-126 g1.9 [Source:ZFIN;Acc:ZDB-GENE-030131-9862] & -2.79689496 & 1.53E-18 \\
\hline havcr1 & hepatitis A virus cellular receptor 1 [Source:ZFIN;Acc:ZDB-GENE-040718-131] & -7.67482315 & 1.91E-18 \\
\hline slc1a8b & solute carrier family 1 (glutamate transporter), member 8b [Source:ZFIN;Acc:ZDB-GENE-070912-552] & -2.5380374 & 3.55E-18 \\
\hline csf1ra & colony stimulating factor 1 receptor, a [Source:ZFIN;Acc:ZDB-GENE-001205-1] & -4.24059459 & 1.94E-17 \\
\hline si:ch211-250 g4.3 & si:ch211-250 g4.3 [Source:ZFIN;Acc:ZDB-GENE-060503-506] & -7.55964405 & 3.53E-17 \\
\hline arpc1b & actin related protein 2/3 complex, subunit 1B [Source:ZFIN;Acc:ZDB-GENE-030131-7414] & -4.66326368 & $6.41 \mathrm{E}-17$ \\
\hline СТ826376.1 & Uncharacterized protein [Source:UniProtKB/TrEMBL;Acc:E7F690] & -2.34407255 & 7.14E-17 \\
\hline pdcb & phosducin b [Source:ZFIN;Acc:ZDB-GENE-031023-2] & -2.4532108 & 9.01E-17 \\
\hline opn1lw2 & opsin 1 (cone pigments), long-wave-sensitive, 2 [Source:ZFIN;Acc:ZDB-GENE-040718-141] & -2.76413479 & 5.15E-16 \\
\hline ba1 & ba1 globin [Source:ZFIN;Acc:ZDB-GENE-990415-18] & -6.23069882 & $6.15 E-16$ \\
\hline opn1mw3 & opsin 1 (cone pigments), medium-wave-sensitive, 3 [Source:ZFIN;Acc:ZDB-GENE-030728-6] & -2.56365947 & 9.40E-16 \\
\hline hbaa1 & hemoglobin alpha adult-1 [Source:ZFIN;Acc:ZDB-GENE-980526-79] & -6.44638081 & 2.14E-15 \\
\hline zgc:195,245 & zgc:195,245 [Source:ZFIN;Acc:ZDB-GENE-081022-200] & -2.62839443 & 2.47E-15 \\
\hline arr3a & arrestin 3a, retinal (X-arrestin) [Source:ZFIN;Acc:ZDB-GENE-040718-102] & -3.02133496 & 2.47E-15 \\
\hline zgc:100,919 & zgc:100,919 [Source:ZFIN;Acc:ZDB-GENE-040718-248] & -4.70079878 & 3.07E-15 \\
\hline gc3 & guanylyl cyclase 3 [Source:ZFIN;Acc:ZDB-GENE-011128-9] & -2.32749631 & 4.00E-15 \\
\hline ppp1r18 & protein phosphatase 1, regulatory subunit 18 [Source:ZFIN;Acc:ZDB-GENE-060503-350] & -2.29809174 & $5.42 \mathrm{E}-15$ \\
\hline CD68 & CD68 molecule [Source:HGNC Symbol;Acc:1693] & -3.83135448 & $5.42 \mathrm{E}-15$ \\
\hline il $1 \mathrm{~b}$ & interleukin 1, beta [Source:ZFIN;Acc:ZDB-GENE-040702-2] & -4.3585252 & $5.67 E-15$ \\
\hline cplx4a & complexin 4a [Source:ZFIN;Acc:ZDB-GENE-060526-116] & -2.12559816 & $7.51 \mathrm{E}-15$ \\
\hline cnga3a & cyclic nucleotide gated channel alpha 3a [Source:ZFIN;Acc:ZDB-GENE-090611-2] & -2.2388126 & 1.69E-14 \\
\hline ccr9a & chemokine (C-C motif) receptor 9a [Source:ZFIN;Acc:ZDB-GENE-060130-125] & -4.13641441 & $1.75 \mathrm{E}-14$ \\
\hline opn1lw1 & opsin 1 (cone pigments), long-wave-sensitive, 1 [Source:ZFIN;Acc:ZDB-GENE-990604-41] & -2.8443546 & 1.89E-14 \\
\hline KEL & Kell blood group, metallo-endopeptidase [Source:HGNC Symbol;Acc:6308] & -8.54223593 & 2.27E-14 \\
\hline
\end{tabular}


Table 4 Top 50 transcripts significantly downregulated (depleted) in GFP+ (rods) vs GFP- retinal cell populations (Continued)

\begin{tabular}{|c|c|c|c|}
\hline Name & Description & $\operatorname{logFC}$ & FDR \\
\hline si:ch1073-403i13.1 & si:ch1073-403i13.1 [Source:ZFIN;Acc:ZDB-GENE-100921-25] & -4.50874649 & $2.31 \mathrm{E}-14$ \\
\hline wasb & Wiskott-Aldrich syndrome (eczema-thrombocytopenia) b [Source:ZFIN;Acc:ZDB-GENE-030131-7098] & -5.26157912 & $2.52 \mathrm{E}-14$ \\
\hline SLC24A2 (1 of 2) & solute carrier family 24 (sodium/potassium/calcium exchanger), member 2 [Source:HGNC Symbol;Acc:10,976] & -2.22076034 & 2.67E-14 \\
\hline pbxip1b & pre-B-cell leukemia homeobox interacting protein 1b [Source:ZFIN;Acc:ZDB-GENE-070112-2032] & -2.27917445 & $3.27 E-14$ \\
\hline CD53 & CD53 molecule [Source:HGNC Symbol;Acc:1686] & -5.72855472 & $3.28 \mathrm{E}-14$ \\
\hline slc25a25a & solute carrier family 25 (mitochondrial carrier; phosphate carrier), member 25a [Source:ZFIN;Acc:ZDB-GENE-040426-2396] & -2.50025348 & $3.72 \mathrm{E}-14$ \\
\hline
\end{tabular}

rod population of larval zebrafish would be distinct from the accumulated (and generally older) rod population of adult zebrafish. A subset of the selected transcripts that were $\mathrm{qPCR}$ validated in adult zebrafish, were therefore evaluated further by qPCR in GFP+ vs. GFP- retinal cell populations obtained from larval zebrafish sacrificed at $14 \mathrm{dpf}$ (days post-fertilization), and juvenile zebrafish sacrificed at $30 \mathrm{dpf}$. Rod photoreceptors are considered morphologically mature at $15 \mathrm{dpf}$ [46], but do not contribute to adult-like scotopic (rod-driven) electroretinogram responses until $29 \mathrm{dpf}$ [47], and so these sampling times were also selected to represent stages in the functional maturation of rods. The xops:eGFP transgenic line is known to show rod-specific transgene expression throughout the zebrafish lifespan [26], and so was considered appropriate as source material for these analyses.

In general, the relative expression levels of selected rod-enriched transcripts within the GFP+ vs. GFP- cell populations were remarkably stable from larval through adult stages (Fig. 4a). However, rho transcripts appeared more highly enriched in rods of adult zebrafish than in rods of larval or juvenile zebrafish, suggesting that rods of adults may accumulate transcript at higher levels than rods of younger fish. Rhol (rhodopsin-like) transcripts showed the opposite trend (Fig. 4a), consistent with the recent findings of Morrow et al. [48], who detected limited expression of rhol in adult retina. Other transcripts more highly enriched in the rods of younger fish were gngt1, ngf, and aipl1. Transcripts present, or present but significantly depleted in adult rods, were less consistent over the lifespan; notable were $r x r g a$ and $m e f 2 c a$, which were not differentially expressed in GFP+ vs. GFP- cells of larvae or juveniles, but were significantly downregulated (depleted) in rods of older zebrafish (Fig. 4b). Rodspecific functions for the encoded nuclear hormone receptor may be distinctive for rods of younger vs. older zebrafish.

We next measured expression (by qPCR) of selected transcripts in whole retinas obtained from WT zebrafish and from xops:mCFP zebrafish, which show a chronic rod degeneration that stimulates proliferation of a rod precursor population [37]. We anticipated that transcripts identified in the present study as rod-enriched, would be upregulated in WT retinas (containing mature rods) vs. xops:mCFP retinas (not containing mature rods). This was true for rho, rhol, dscamb, and $n g f$, but not true for esrrd, $n r l$, and $n r 2 f 1 b$, which were not differentially expressed in WT vs. xops:mCFP retinas (Fig. 5a). It is possible that the latter genes may have other retinal functions in the response to the chronic loss of rods. We also tested two transcripts present (but not enriched) in rods, rxrgb and Lplastin, and these were both significantly differentially downregulated in WT vs. xops:mCFP retinas (Fig. 5b), again suggestive of roles in response to chronic loss of rods. Two transcripts depleted in rods, and known to be expressed in cones in zebrafish or other model organisms, rxrga and thrb [45, 49-51], were not differentially expressed in WT vs. xops:mCFP retinas, consistent with their likely predominant localization to cones, which are unaffected in the xops:mCFP zebrafish [9]. Differentially expressed genes in WT vs. xops:mCFP retinas have previously been identified using microarray (GEO Acc \# GSE22221) [37], allowing a deeper comparison of the two datasets. Using a cutoff of $p<0.01$ for both datasets returned 94 shared entries (Fig. 5c; Additional file 1: Table S1), including known photoreceptor genes aanat1, pde6a, rom $1 a$, and rom $1 b$. We believe the number shared by the datasets is limited to 94 transcripts is in part due to the incomplete representation of zebrafish transcripts on the Agilent chip used for the microarray study.

Selected transcripts were further examined by in situ hybridization to visualize spatial expression patterns. For these studies we selected rhol and dscamb as rodenriched transcripts, and rxrga and rxrgb as transcripts present in rods (Fig. 6). The expression pattern of rho is shown for reference as an example of a rod-exclusive hybridization pattern (Fig. 6a). Rhol (rh1-2) was previously detected as a second rho gene in zebrafish [52] and other teleost fish [48], with demonstrated phototransduction functions and expression in the photoreceptor layer [48]. In the present study we have confirmed that rhol is expressed (and enriched) in rods, based upon RNA-seq and qPCR of purified rods (Fig. $6 \mathrm{~b})$. In tissues sampled at $14 \mathrm{dpf}$, rhol was expressed in the photoreceptor layer, in a subset of cells matching the distribution of rods, but restricted primarily to the peripheral retina. This predominantly peripheral pattern 

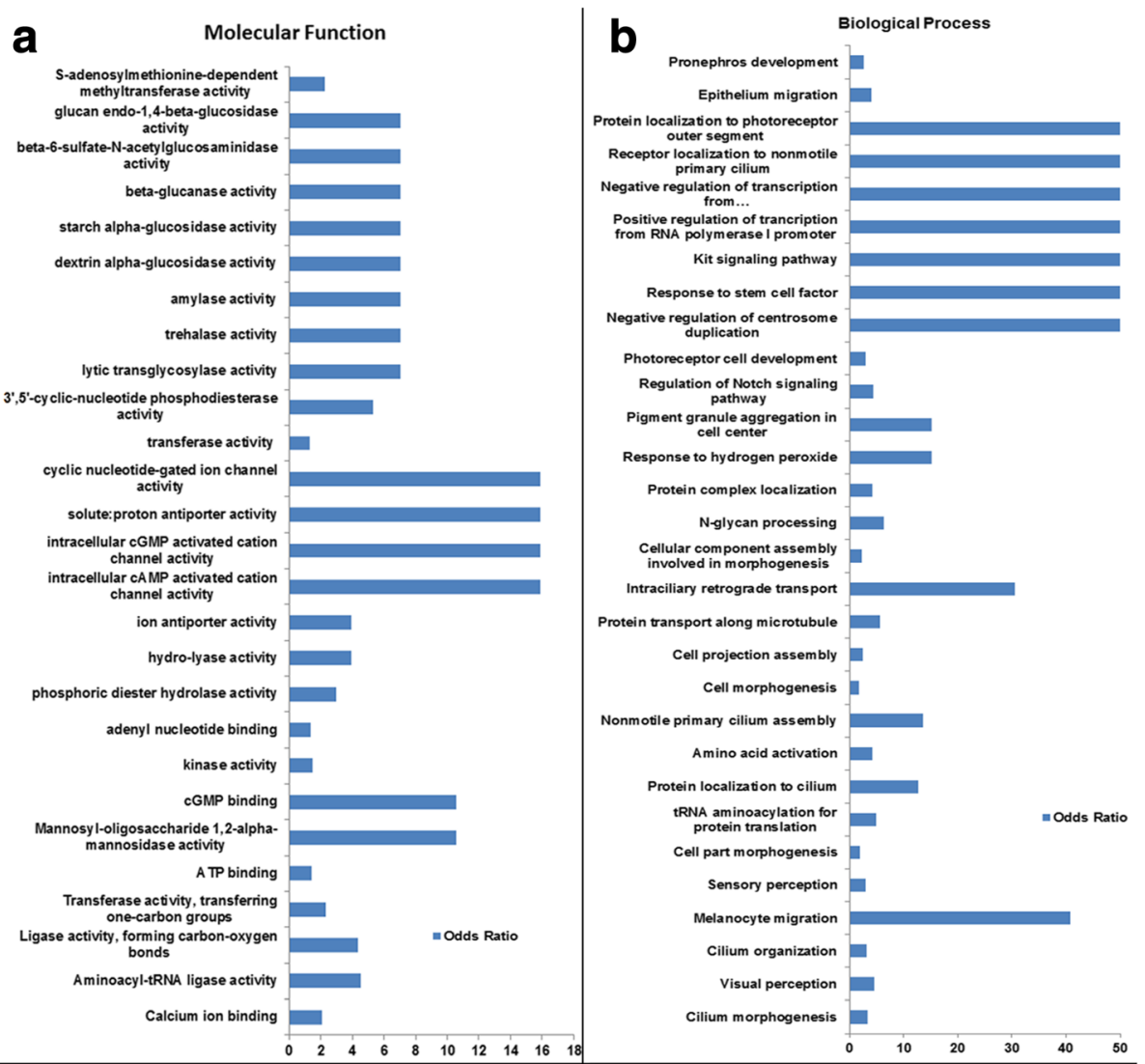

Pigment granule aggregation in

Response to hydrogen peroxide

Protein complex localization

N-glycan processing

Cellular component assembly
involved in morphogenesis

Intraciliary retrograde trans port

Protein transport along microtubule

Cell projection assembly

Cell morphogenesis

Nonmotile primary cilium assembly

Amino acid activation

Protein localization to cilium

TRNA aminoacylation for -
protein translation

Cell part morphogenesis

Sensory perception

Sensory perception

Cilium organization

Visual perception

Cilium morphogenesis

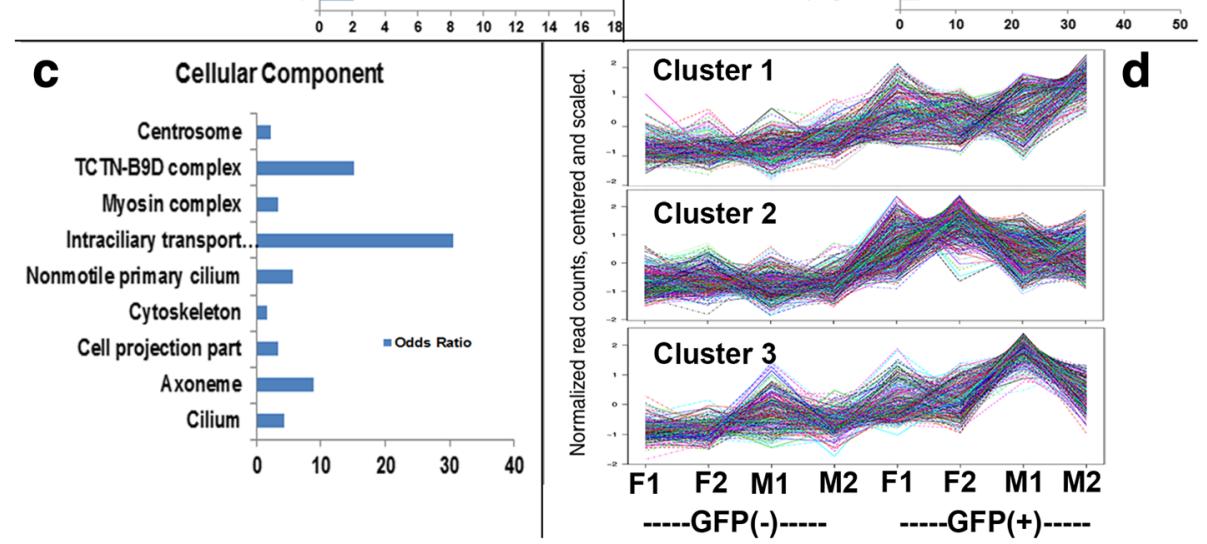

Fig. 2 Gene ontology (GO) and hierarchical cluster analysis. a-c Molecular functions (a), biological processes (b), and cellular components (c) overrepresented in the GFP+ (rod photoreceptor) cell population $(p<0.01)$. d Hierarchical clustering of rod-enriched transcripts reveals only three, highly similar clusters. F, female; M, male

was evident in retinas sampled at 1 month, and in adult retina, where only very weak expression was detected in central retina (Fig. 6b). In retinas of the xops:mCFP line that displays rod degeneration, rhol was not detected by in situ hybridization, even though some developing/ dying rho-expressing cells are present (Fig. 6b). In rods that express $r h o l$, the timing of expression may be delayed as compared with rho (rho is first expressed embryonically, while rhol is first expressed in larvae [52]), and rods of xops:mCFP zebrafish may simply not survive long enough to express rhol.
Dscamb is one of two zebrafish orthologues of mammalian Dscam. Mammalian Dscam encodes a homophilic cell adhesion molecule with numerous roles in retinal cell patterning and refinement of circuitry [53, 54], but is not expressed in mouse rods [55] (although dscamlike1 is expressed in mouse rods; [56]. In larval and juvenile zebrafish retinas, dscamb was expressed in some cells of the outer nuclear layer (photoreceptor layer; ONL), in a pattern consistent with identities of rods and possibly a subset of cones, and was also seen in the inner nuclear layer (INL) and ganglion cell layer (GCL) in a 

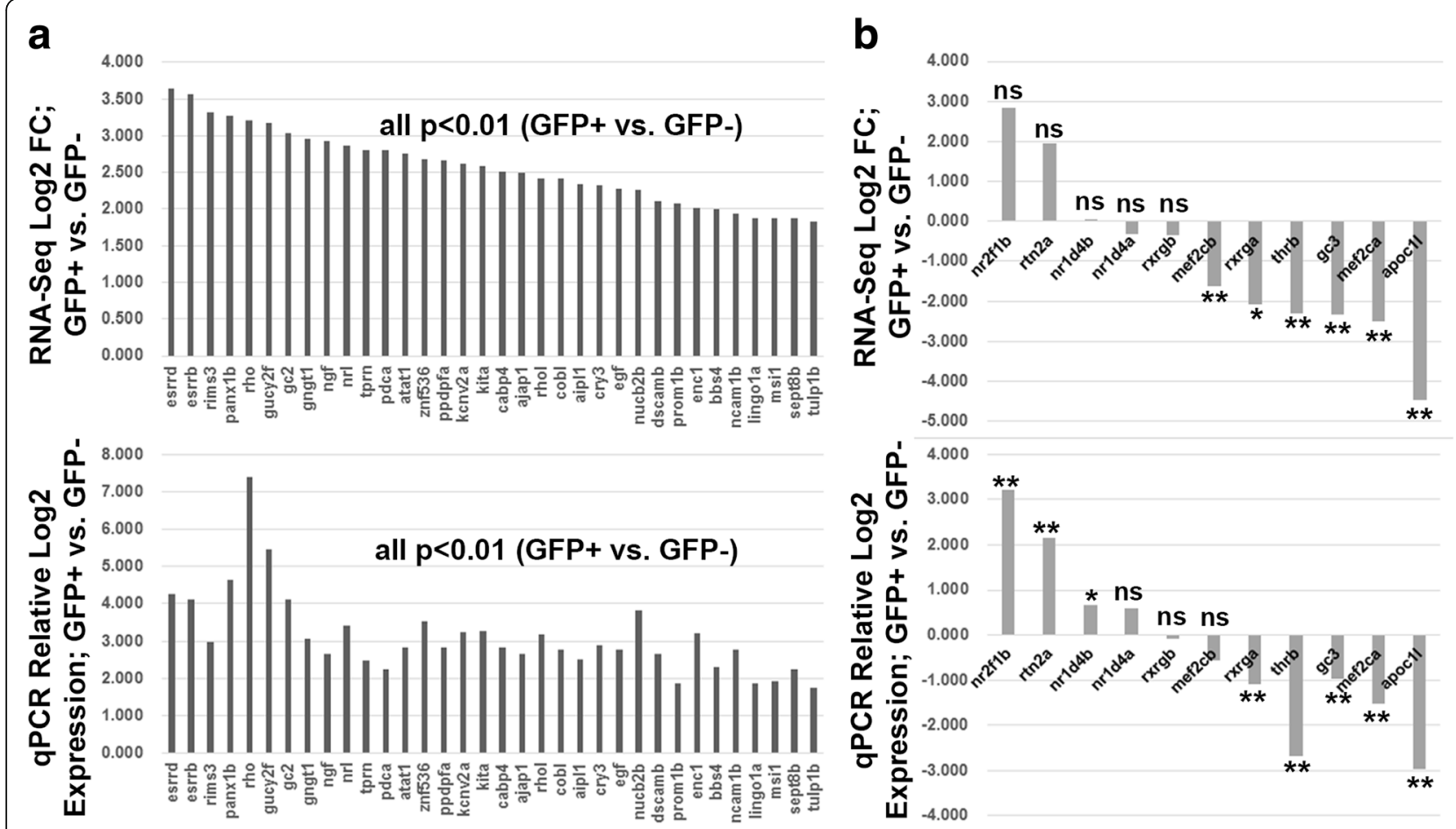

Fig. 3 Quantitative PCR (qPCR) validation of transcripts enriched in GFP+ (rod photoreceptor) cells (a), and present or depleted in GFP+ cells (b). Top panel in each shows RNA-Seq results; bottom panel shows qPCR. ${ }^{* *}, p<0.01 ;{ }^{*}, p<0.05$; ns, not significantly differentially expressed, for GFP+ vs. GFP- (three biological replicates)

pattern suggestive of amacrine cells (Fig. 6c). Expression of dscamb in adult zebrafish retinas showed similar patterns (Fig. 6c). The xops:mCFP retinas showed apparently greatly reduced expression in the photoreceptor layer, consistent with dscamb localization to rods (Fig. 6c).

In larval and juvenile zebrafish, rxrga and rxrgb were both diffusely expressed in all retinal cellular layers, and more strongly localized to the far peripheral photoreceptor layer and the stem/progenitor cell-containing CMZ (Fig. 6d, e). The former pattern suggests transient higher expression in newly-generated photoreceptors, consistent with our previous report of expression of transient expression of rxrga in photoreceptors of zebrafish embryos [57]. Juvenile and adult zebrafish WT retinas, and those of xops:mCFP fish, both showed a diffuse pattern throughout all cellular layers, although the juvenile samples showed more pronounced expression of rxrga within the GCL and inner INL (Fig. 6d, e). These findings are consistent with the lack of significant enrichment of these transcripts in rods of adult zebrafish as detected by RNA-seq and qPCR (Fig. 3).

\section{Rod photoreceptor transcripts in regenerated retina}

The zebrafish regenerates a functional retina following widespread damage due to intravitreal injection of the neurotoxin ouabain [11]. However, regenerated fish retinas display histological errors such as neuronal cell bodies present in plexiform layers [14, 15] (and see Fig. 7), and disruptions of two-dimensional patterning

Table $\mathbf{5}$ Sex $X$ rod interaction

\begin{tabular}{lllll}
\hline Name & Description & logFC & FDR & Comment \\
\hline pmela & premelanosome protein a [Source:ZFIN;Acc:ZDB-GENE-030131-9818] & 15.0198 & $6.05 E-06$ & $\begin{array}{l}\text { Absent in female rods; Present in male } \\
\text { rods }\end{array}$ \\
slc6a6b & $\begin{array}{l}\text { solute carrier family 6 (neurotransmitter transporter, taurine), member 6b } \\
\text { [Source:ZFIN;Acc:ZDB-GENE-030131-3077] }\end{array}$ & -4.06708 & 3.31 E-05 $\begin{array}{l}\text { Enriched in female rods; depleted in } \\
\text { male rods }\end{array}$ \\
naa35 & N(alpha)-acetyltransferase 35, NatC auxiliary subunit [Source:ZFIN;Acc:ZDB-GENE-030131-306] & -5.25565 & $0.025774 \begin{array}{l}\text { Enriched in female rods; depleted in } \\
\text { male rods }\end{array}$ \\
si:ch211- & si:ch211-89f7.1 [Source:ZFIN;Acc:ZDB-GENE-060526-180] & -2.75147 & $0.025774 \begin{array}{l}\text { Enriched in female rods; less enriched } \\
\text { in male rods }\end{array}$ \\
89f7.1 & Usher syndrome 2A (autosomal recessive, mild) [Source:ZFIN;Acc:ZDB-GENE-060503-794] & -2.65862 & 0.025941 & $\begin{array}{l}\text { Enriched in female rods; not enriched } \\
\text { in male rods }\end{array}$ \\
\hline
\end{tabular}



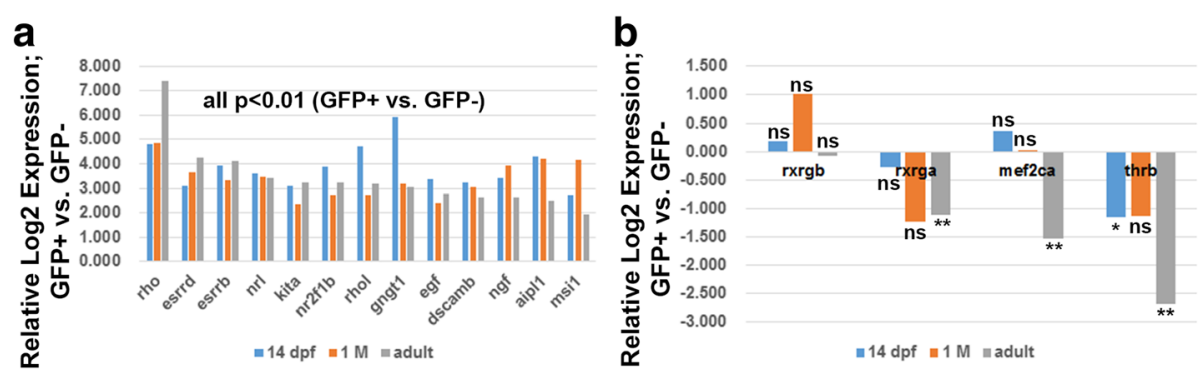

Fig. 4 A. QPCR of selected transcripts enriched (a), or present (and not differentially expressed) or present (and depleted) in GFP+ (rod photoreceptor) cells $(\mathbf{b})$, in larval retinas (14 dpf), juvenile retinas (1 M), and adult retinas. ${ }^{*}, p<0.01 ;{ }^{*}, p<0.05$; ns, not significantly differentially expressed, for GFP+ vs. GFP- (three biological replicates)

[58, 59]. Although microarray and other analyses have revealed transcriptional changes in whole retina in response to damage [60] and accompanying the proliferative response specifically of Müller glia [60-62], the molecular signatures of identified, regenerated retinal neurons have never been compared with those of native, undamaged retinal neurons. We sampled regenerated retinas at $14 \mathrm{dpi}$, a time when all retinal layers are known to be re-established, but with some histological errors and very thin plexiform layers [11]. Another set of regenerated retinas was sampled at $30 \mathrm{dpi}$, when plexiform layers have expanded, but histological errors remain. The fidelity of xops:eGFP reporter expression as rod-specific in regenerated retina has not, to our knowledge, been established. Therefore we processed retinal cryosections for visualization of the eGFP reporter together with staining by the 1D1 (anti-rhodopsin; [40]) monoclonal antibody, using confocal microscopy. GFP+ profiles were observed in the ONL of control retinas, and of $14 \mathrm{dpi}$ and $30 \mathrm{dpi}$ retinas, and were associated with DAPI+ nuclei (Fig. 7a-i, asterisks). This localization to the ONL is consistent with their identities as rods. Furthermore, 1D1+ outer segments in control and regenerated retina were co-labeled with GFP (Fig. 7b-d, f$\mathrm{h}, \mathrm{j}-\mathrm{l}$, arrowheads), suggesting that regenerated, GFP+ cells in the xops:eGFP zebrafish retina corresponded to regenerated rods.

Regenerated xops:eGFP retinas were dissociated, FACS-sorted, and subjected to qPCR of selected transcripts. Transcripts that were detected as significantly rod-enriched in undamaged retinas were also significantly rod-enriched in regenerated retinas at 14 and 30 dpi (Fig. 8a), providing an initial indication that regenerated rods are similar at the transcript level as the undamaged rods. Both rho and rhol were more highly enriched in the regenerating rods, and $\mathrm{nrl}$ was more highly enriched at 14 dpi (Fig. 8a). Rxrgb was detected, but not differentially expressed, in all samples, while rxrga was significantly depleted in rods of undamaged retina and at $14 \mathrm{dpi}$, but not $30 \mathrm{dpi}$ (Fig. 8b). Thrb,

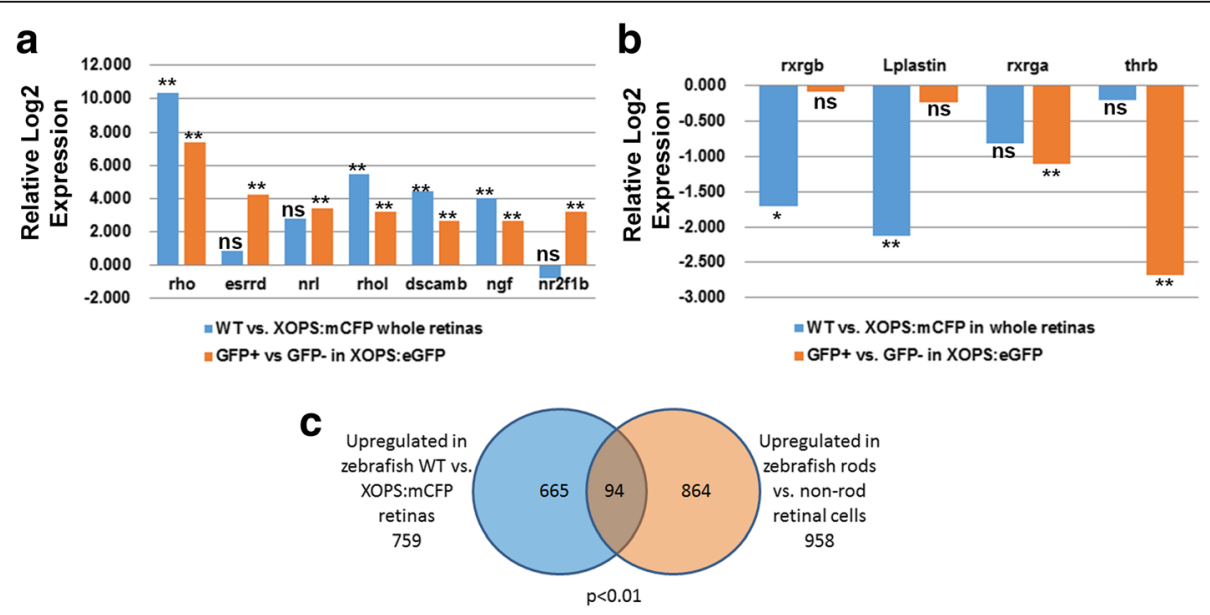

Fig. 5 qPCR of selected transcripts enriched (a), or present (and not differentially expressed) or present (and depleted) in GFP+ (rod photoreceptor) cells (b), and relative expression in WT vs. xops:mCFP retinas. ${ }^{*}, \mathrm{p}<0.01 ;{ }^{*}, \mathrm{p}<0.05$; ns, not significantly differentially expressed for GFP+ vs. GFP- cells, or for WT vs. xops:mCFP retinas (three biological replicates). c Numbers of unique transcripts upregulated in GFP+ vs. GFPretinal cells (present study), those upregulated in WT vs. xops:mCFP retinas [37], at $p<0.01$, and those shared by both sets 


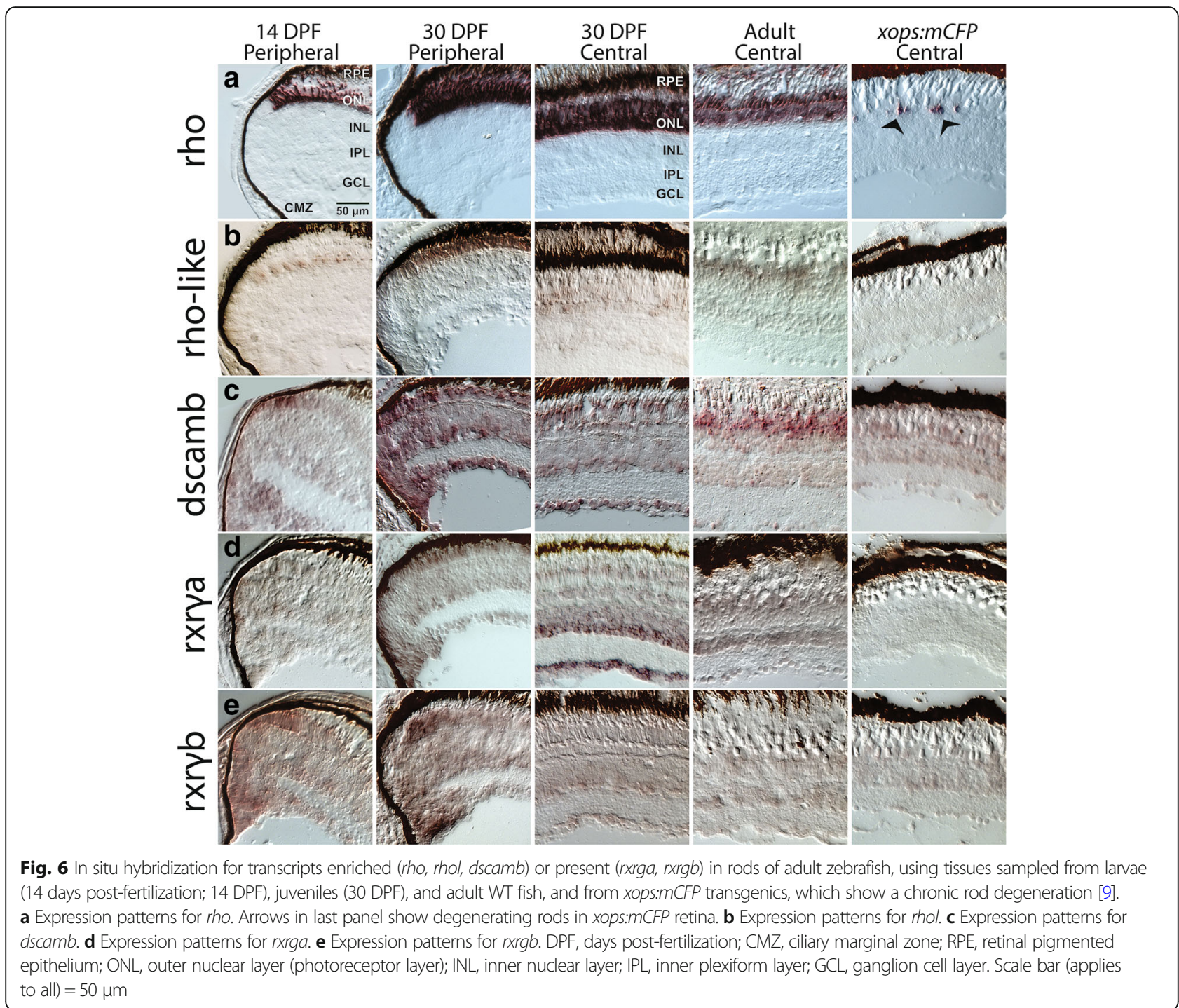

important for determination of red-sensitive cones [51] was detected, but highly significantly depleted in all samples (Fig. 8b). Together these findings suggest that the rod transcriptome in regenerated retina possibly carries a molecular signature similar to that of undamaged rods.

\section{Discussion}

We report for the first time, transcripts enriched, present, and depleted in rod photoreceptors of the adult zebrafish retina, now available as a resource for other investigators with interests in rod health, structure, function, and neurogenesis. The dataset was validated by qPCR of 45 transcripts, and many transcripts present in rods were not previously recognized as rod-enriched. Analysis of FACS-sorted fluorescent rods from transgenic zebrafish appears to be an excellent approach for expanding our knowledge of rod biology, and in the future may be applied to other photoreceptor subpopulations [63], since there are numerous transgenic tools available that selectively fluorescently label specific cone subtypes [64, 65].

The rod transcriptome appears to be remarkably stable over the zebrafish lifespan, at least for the rod-enriched transcripts studied in this manner, and at the sampling times used. The rod population of adult zebrafish, which includes the rods generated larvally - these rods are nearly as old as the zebrafish themselves - as well as the many rods that accumulated through adulthood, likely carries a molecular signature similar to that of the newly-generated rods of larval retina. The potential exceptions are the transcripts encoding the visual pigment proteins themselves, rho and rhol. Rho is more abundant in the rods from older fish, where the rod population includes many older rods. However, rhol is more abundant in those of younger fish. Interestingly, the peak spectral sensitivity of rhol is shifted $5 \mathrm{~nm}$ shorter than that of 


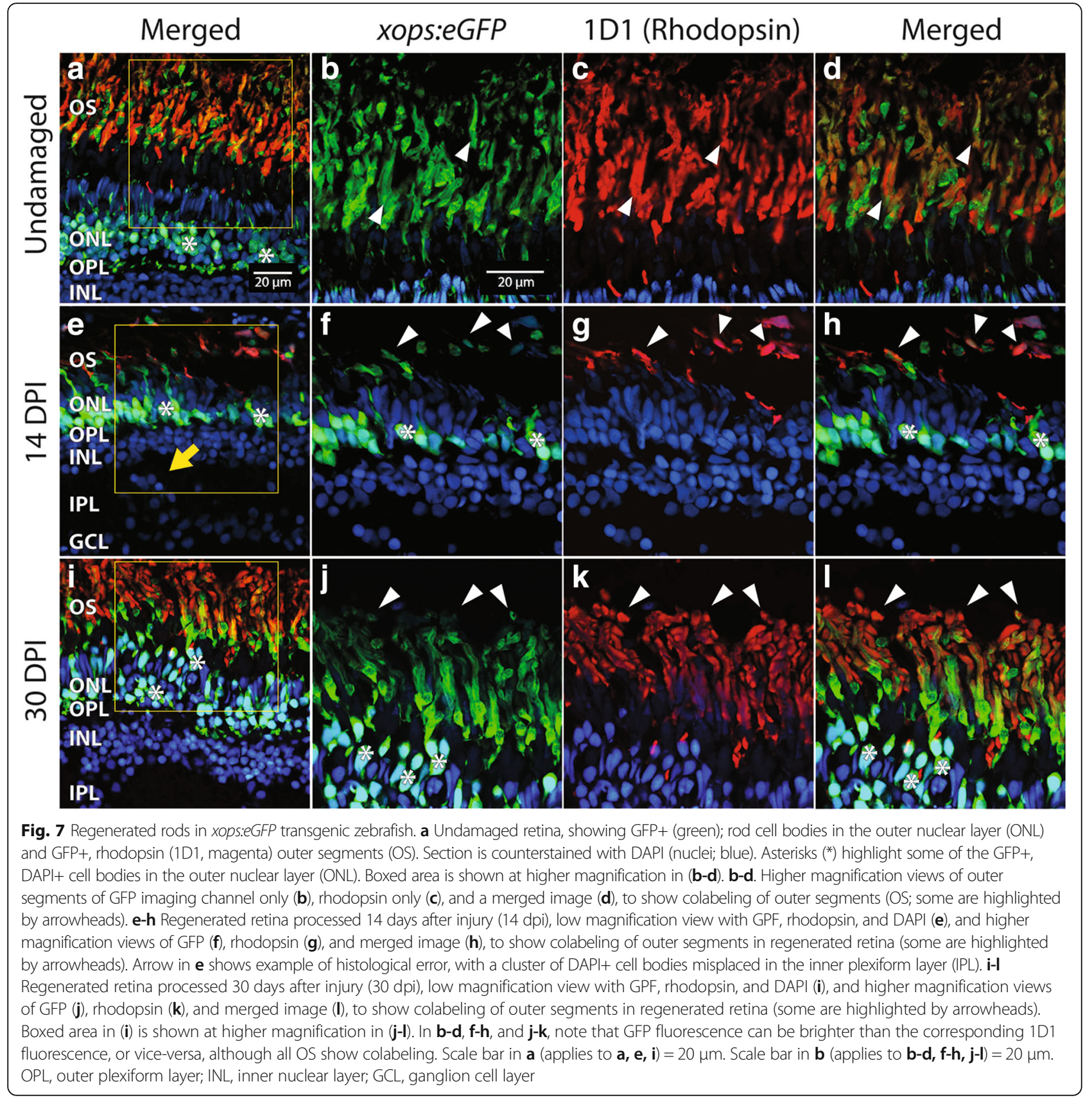

rho [48], although it is not known whether this difference is meaningful in the visual environment of zebrafish when rods are utilized. It is possible that the higher levels of $r h o l$ in rods of younger zebrafish are important for a visually-mediated behavior such as a prey capture strategy, that is different in larval/juvenile vs. adult zebrafish [66]. Extending the unbiased RNA-seq approach for the study of rod transcripts over the zebrafish lifespan may reveal other functional changes.

We used two approaches to evaluate rod transcripts in situations where the zebrafish retina responds to rod damage. In the first approach, we analyzed selected rod- enriched, and rod-depleted genes in WT retinas vs. those with chronic loss and attempted replacement of rods (xops:mCFP) [9]. Some of these rod-enriched transcripts were upregulated in WT retinas vs. xops:mCFP, consistent with the lack of mature rods in the $x o p s: m C F P$ retinas. However, some were not, pointing to alternative roles for these transcripts in some aspect of the response to chronic damage, for example in the environment of high levels of cell death, or in upregulation of rod precursor proliferation. The second approach was to analyze selected rod-enriched, and rod-depleted genes following widespread retinal damage and a regeneration 

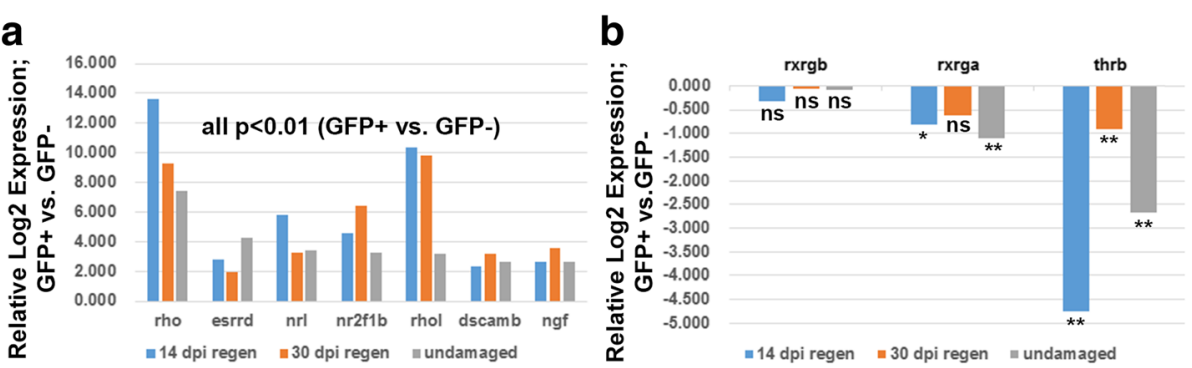

Fig. 8 qPCR of selected transcripts enriched (a), or present (and not differentially expressed) or present (and depleted) in GFP+ (rod photoreceptor) cells (b), in regenerated retinas at 14 days post-injury (dpi), 30 dpi, and in undamaged retinas. ${ }^{*}, \mathrm{p}<0.01$; ${ }^{*}, \mathrm{p}<0.05$; ns, not significantly differentially expressed, for GFP+ vs. GFP- (three biological replicates)

period. We found that transcripts enriched in undamaged, native rods, also were enriched in regenerated rods. Again the extension of the unbiased RNA-seq approach is likely to be even more illuminating, but this initial result suggests that regenerated rods do not differ in expression of a set of selected transcripts in comparison with undamaged, native rods. This finding implies that regenerated retinal neurons may not carry with them alternative molecular signatures, and likely recover their distinctive functions [67].

\section{Conclusions}

We report the generation and validation of an RNA-seq dataset describing the rod transcriptome of the zebrafish. This transcriptome appears stable across the zebrafish lifespan, and similar in regenerated rods as compared with undamaged rods. Future applications of this study include comparative photoreceptor transcriptomics (rods vs. each cone subtype), and comparative analysis with transcriptome information available from other model organisms including mouse [68], as well as from stem cell-derived human retinal organoids [69]. Such studies have potential to reveal further distinctions of cones vs. rods, and distinctions among vertebrates that may resolve questions of vertebrate photoreceptor evolution [25, 70-72].

\section{Additional file}

Additional file 1: Supplemental Figure S1. A. Multidimensional scaling (MDS) plot to visualize the level of similarity among the eight samples (four GFP+ and four GFP-) analyzed by RNA-seq. B. Average log counts per million (CPM) as a function of biological coefficient of variation (BCV), indicating a trend in dispersion associated with expression. C. Smear plot highlighting (red) differentially expressed transcripts at FDR $<0.05$. Table $\mathbf{S 1}$. Transcripts detected as significantly upregulated $(p<0.01)$ in GFP+ vs. GFP- retinal cells of xops:eGFP zebrafish ("rod enriched"), and also detected as significantly upregulated $(p<0.01)$ in WT vs. Xops:mCFP whole retinas. (DOCX $262 \mathrm{~kb})$

\section{Abbreviations}

CGZ: Circumferential germinal zone; CMZ: Ciliary marginal zone; DPF: Days post-fertilization; DPI: Days post-injury; FACS: Fluorescence-Activated Cell Sorting; GCL: Ganglion cell layer; GO: Gene ontology; INL: Inner nuclear layer; ONL: Outer nuclear layer; WT: Wild-type

\section{Acknowledgments}

The authors are grateful to Dr. James Fadool for the xops:eGFP zebrafish, to Dr. Ann Morris for the xops:mCFP zebrafish, to Ms. Ann Norton of the UI IBEST Optical Imaging Core for assistance with FACS, to Mr. Dan New and Dr. Sam Hunter of the UI IBEST Genomics Core for RNA-Seq and assistance with bioinformatics. We thank Ruth Frey, William Thurston, Kirsie Lundholm (Stenkamp lab), and Joshua Sukeena (Fuerst lab) for technical assistance, and Dr. Diana Mitchell for retinal lesioning and for critical evaluation of earlier versions of the manuscript. The IBEST (Institute for Bioinformatics and Evolutionary Studies) Genomics Core is supported by NIH COBRE P30 GM103324.

\section{Funding}

Funding was provided by NIH R01 EY012346 (DLS), NIH R21 EY026814 (DLS), a Technology Access Grant (CS and DLS) available through Idaho's NIH-INBRE program (supported by NIH P20 GM103408), and the Malcolm and Carol Renfrew Faculty Fellowship (DLS). These funding bodies did not have roles in the design of the study and collection, analysis, and interpretation of data and in writing the manuscript.

\section{Availability of data and materials}

The RNA-Seq dataset is available at GEO under accession \# GSE100062. Other data generated or analyzed during this study are included in this article and its additional information files.

\section{Authors' contributions}

CS performed animal husbandry, FACS-sorting, RNA isolation, and gPCR, and contributed to writing the manuscript. CG performed animal husbandry, tissue processing, probe preparation, and in situ hybridization, confocal microscopy, and contributed to writing the manuscript. DLS and CS conceived of the study, and

DLS wrote the manuscript. All authors read and approved the final manuscript.

Ethics approval and consent to participate

All studies involving zebrafish were approved by the University of Idaho's Animal Care and Use Committee.

\section{Consent for publication}

Not applicable.

\section{Competing interests}

The authors declare that they have no competing interests.

\section{Publisher's Note}

Springer Nature remains neutral with regard to jurisdictional claims in published maps and institutional affiliations.

Received: 25 July 2017 Accepted: 28 January 2018

Published online: 08 February 2018

\section{References}

1. May-Simera H, Nagel-Wolfrum K, Wolfrum U. Cilia - the sensory antennae in the eye. Prog Retin Eye Res. 2017;60:144-18. 
2. Nemet I, Ropelewski P, Imanishi Y. Rhodopsin trafficking and Mistrafficking: signals, molecular components, and mechanisms. Prog Mol Biol Transl Sci. 2015;132:39-71.

3. Nash BM, Wright DC, Grigg JR, Bennetts B, Jamieson RV. Retinal dystrophies, genomic applications in diagnosis and prospects for therapy. Transl Pediatr. 2015:4(2):139-63.

4. Stenkamp DL. The rod photoreceptor lineage of teleost fish. Prog Retin Eye Res. 2011;30(6):395-404.

5. Stenkamp DL. Neurogenesis in the fish retina. Int Rev Cytol. 2007;259:173224.

6. Marcus RC, Delaney CL, Easter SS Jr. Neurogenesis in the visual system of embryonic and adult zebrafish (Danio Rerio). Off. Vis Neurosci. 1999;16(3): 417-24.

7. Raymond PA, Barthel LK, Bernardos RL, Perkowski JJ. Molecular characterization of retinal stem cells and their niches in adult zebrafish. BMC Dev Biol. 2006;6:36

8. Bernardos RL, Barthel LK, Meyers JR, Raymond PA. Late-stage neuronal progenitors in the retina are radial Muller glia that function as retinal stem cells. J Neurosci. 2007;27(26):7028-40.

9. Morris AC, Schroeter EH, Bilotta J, Wong RO, Fadool JM. Cone survival despite rod degeneration in XOPS-mCFP transgenic zebrafish. Invest Ophthalmol Vis Sci. 2005;46(12):4762-71.

10. Montgomery JE, Parsons MJ, Hyde DR. A novel model of retinal ablation demonstrates that the extent of rod cell death regulates the origin of the regenerated zebrafish rod photoreceptors. J Comp Neurol. 2011;518(6):800-14.

11. Sherpa T, Fimbel SM, Mallory DE, Maaswinkel H, Spritzer SD, Sand JA, Li L, Hyde DR, Stenkamp DL. Ganglion cell regeneration following whole-retina destruction in zebrafish. Dev Neurobiol. 2008;68(2):166-81.

12. Fimbel SM, Montgomery JE, Burket $C T$, Hyde DR. Regeneration of inner retinal neurons after intravitreal injection of ouabain in zebrafish. J Neurosci. 2007;27(7):1712-24.

13. Nagashima M, Barthel LK, Raymond PA. A self-renewing division of zebrafish Muller glial cells generates neuronal progenitors that require $\mathrm{N}$-cadherin to regenerate retinal neurons. Development. 2013;140(22):4510-21.

14. Powell C, Cornblath E, Elsaeidi F, Wan J, Goldman D. Zebrafish Muller gliaderived progenitors are multipotent, exhibit proliferative biases and regenerate excess neurons. Sci Rep. 2016;6:24851.

15. Sherpa T, Lankford T, McGinn TE, Hunter SS, Frey RA, Sun C, Ryan M, Robison BD, Stenkamp DL. Retinal regeneration is facilitated by the presence of surviving neurons. Dev Neurobiol. 2014;74(9):851-76.

16. Nelson SM, Frey RA, Wardwell SL, Stenkamp DL. The developmental sequence of gene expression within the rod photoreceptor lineage in embryonic zebrafish. Dev Dyn. 2008;237(10):2903-17.

17. Morris AC, Scholz T, Fadool JM. Rod progenitor cells in the mature zebrafish retina. Adv Exp Med Biol. 2008;613:361-8.

18. Otteson DC, D'Costa AR, Hitchcock PF. Putative stem cells and the lineage of rod photoreceptors in the mature retina of the goldfish. Dev Biol. 2001; 232(1):62-76.

19. Julian D, Ennis K, Korenbrot JI. Birth and fate of proliferative cells in the inner nuclear layer of the mature fish retina. J Comp Neurol. 1998;394(3):271-82.

20. Mack AF, Papanikolaou D, Lillo C. Investigation of the migration path for new rod photoreceptors in the adult cichlid fish retina. Exp Neurol. 2003; 184(1):90-6.

21. Morris AC, Fadool JM. Studying rod photoreceptor development in zebrafish. Physiol Behav. 2005;86(3):306-13.

22. Hitchcock P, Kakuk-Atkins L. The basic helix-loop-helix transcription factor neuroD is expressed in the rod lineage of the teleost retina. J Comp Neurol. 2004;477(1):108-17.

23. Nelson SM, Park L, Stenkamp DL. Retinal homeobox 1 is required for retinal neurogenesis and photoreceptor differentiation in embryonic zebrafish. Dev Biol. 2009;328(1):24-39.

24. Wilson SG, Wen W, Pillai-Kastoori L, Morris AC. Tracking the fate of her4 expressing cells in the regenerating retina using her4:Kaede zebrafish. Exp Eye Res. 2016;145:75-87.

25. Sotolongo-Lopez M, Alvarez-Delfin K, Saade CJ, Vera DL, Fadool JM. Genetic dissection of dual roles for the transcription factor six7 in photoreceptor development and patterning in Zebrafish. PLoS Genet. 2016;12(4):e1005968.

26. Fadool JM. Development of a rod photoreceptor mosaic revealed in transgenic zebrafish. Dev Biol. 2003;258(2):277-90.

27. Westerfield M. The Zebrafish book; a guide for the laboratory use of zebrafish (Danio rerio). 5th ed. Eugene, OR: University of Oregon Press; 2007.
28. Barthel LK, Raymond PA. Improved method for obtaining 3-microns cryosections for immunocytochemistry. J Histochem Cytochem. 1990;38(9): 1383-8.

29. Mitchell DM, Stevens CB, Frey RA, Hunter SS, Ashino R, Kawamura S, Stenkamp DL. Retinoic acid signaling regulates differential expression of the Tandemly-duplicated long wavelength-sensitive cone Opsin genes in Zebrafish. PLoS Genet. 2015;11(8):e1005483.

30. Magoc T, Salzberg SL. FLASH: fast length adjustment of short reads to improve genome assemblies. Bioinformatics. 2011;27(21):2957-63.

31. Li H, Durbin R. Fast and accurate short read alignment with burrowswheeler transform. Bioinformatics. 2009;25(14):1754-60.

32. Li H, Handsaker B, Wysoker A, Fennell T, Ruan J, Homer N, Marth G, Abecasis $\mathrm{G}$, Durbin R, Genome Project Data Processing S. The sequence alignment/ map format and SAMtools. Bioinformatics. 2009;25(16):2078-9.

33. Anders S, Pyl PT, Huber W. HTSeq-a python framework to work with highthroughput sequencing data. Bioinformatics. 2015;31(2):166-9.

34. Team RC: R: a language and environment for statistical computing. 2014.

35. Robinson MD, McCarthy DJ, Smyth GK. edgeR: a bioconductor package for differential expression analysis of digital gene expression data. Bioinformatics. 2010;26(1):139-40.

36. Falcon S, Gentleman R. Using GOstats to test gene lists for GO term association. Bioinformatics. 2007;23(2):257-8.

37. Morris AC, Forbes-Osborne MA, Pillai LS, Fadool JM. Microarray analysis of XOPS-mCFP Zebrafish retina identifies genes associated with rod photoreceptor degeneration and regeneration. Invest Ophthalmol Vis Sci. 2011;52(5):2255-66.

38. Moraru C, Moraru G, Fuchs BM, Amann R. Concepts and software for a rational design of polynucleotide probes. Environ Microbiol Rep. 2011;3(1): $69-78$.

39. Thomas JL, Morgan GW, Dolinski KM, Thummel R. Characterization of the pleiotropic roles of sonic hedgehog during retinal regeneration in adult zebrafish. Exp Eye Res. 2018;166:106-15.

40. Hyatt GA, Schmitt EA, Fadool JM, Dowling JE. Retinoic acid alters photoreceptor development in vivo. Proc Natl Acad Sci U S A. 1996;93(23): 13298-303.

41. Gao Z, Mao CA, Pan P, Mu X, Klein WH. Transcriptome of Atoh7 retinal progenitor cells identifies new Atoh7-dependent regulatory genes for retinal ganglion cell formation. Dev Neurobiol. 2014;74(11):1123-40.

42. Svahn AJ, Graeber MB, Ellett F, Lieschke GJ, Rinkwitz S, Bennett MR, Becker TS. Development of ramified microglia from early macrophages in the zebrafish optic tectum. Dev Neurobiol. 2013;73(1):60-71.

43. Richardson GM, Lannigan J, Macara IG. Does FACS perturb gene expression? Cytometry A. 2015;87(2):166-75.

44. Bellingham J, Chaurasia SS, Melyan Z, Liu C, Cameron MA, Tarttelin EE, luvone PM, Hankins MW, Tosini G, Lucas RJ. Evolution of melanopsin photoreceptors: discovery and characterization of a new melanopsin in nonmammalian vertebrates. PLoS Biol. 2006:4(8):e254.

45. Roberts MR, Hendrickson A, McGuire CR, Reh TA. Retinoid X receptor (gamma) is necessary to establish the S-opsin gradient in cone photoreceptors of the developing mouse retina. Invest Ophthalmol Vis Sci. 2005:46(8):2897-904

46. Branchek T, Bremiller R. The development of photoreceptors in the zebrafish, Brachydanio Rerio. I. Structure. J Comp Neurol. 1984;224(1):107-15.

47. Bilotta J, Saszik S, Sutherland SE. Rod contributions to the electroretinogram of the dark-adapted developing zebrafish. Dev Dyn. 2001:222(4):564-70.

48. Morrow JM, Lazic S, Dixon Fox M, Kuo C, Schott RK, de AGE, Santini F, Tropepe V, Chang BS. A second visual rhodopsin gene, rh1-2, is expressed in zebrafish photoreceptors and found in other ray-finned fishes. J Exp Biol. 2017;220(Pt 2):294-303.

49. Roberts MR, Srinivas M, Forrest D, Morreale de Escobar G, Reh TA. Making the gradient: thyroid hormone regulates cone opsin expression in the developing mouse retina. Proc Natl Acad Sci U S A. 2006:103(16):6218-23.

50. Applebury ML, Farhangfar F, Glosmann M, Hashimoto K, Kage K, Robbins JT, Shibusawa N, Wondisford FE, Zhang H. Transient expression of thyroid hormone nuclear receptor TRbeta2 sets $\mathrm{S}$ opsin patterning during cone photoreceptor genesis. Dev Dyn. 2007;236(5):1203-12.

51. Suzuki SC, Bleckert A, Williams PR, Takechi M, Kawamura S, Wong RO. Cone photoreceptor types in zebrafish are generated by symmetric terminal divisions of dedicated precursors. Proc Natl Acad Sci U S A. 2013;110(37):15109-14.

52. Morrow JM, Lazic S, Chang BS. A novel rhodopsin-like gene expressed in zebrafish retina. Vis Neurosci. 2011;28(4):325-35. 
53. Fuerst PG, Koizumi A, Masland RH, Burgess RW. Neurite arborization and mosaic spacing in the mouse retina require DSCAM. Nature. 2008;451(7177):470-4.

54. Li S, Sukeena JM, Simmons AB, Hansen EJ, Nuhn RE, Samuels IS, Fuerst PG. DSCAM promotes refinement in the mouse retina through cell death and restriction of exploring dendrites. J Neurosci. 2015;35(14):5640-54.

55. de Andrade GB, Long SS, Fleming H, Li W, Fuerst PG. DSCAM localization and function at the mouse cone synapse. J Comp Neurol. 2014;522(11):2609-33.

56. Fuerst PG, Bruce F, Tian M, Wei W, Elstrott J, Feller MB, Erskine L, Singer JH, Burgess RW. DSCAM and DSCAML1 function in self-avoidance in multiple cell types in the developing mouse retina. Neuron. 2009;64(4):484-97.

57. Stevens CB, Cameron DA, Stenkamp DL. Plasticity of photoreceptorgenerating retinal progenitors revealed by prolonged retinoic acid exposure. BMC Dev Biol. 2011;11:51

58. Stenkamp DL, Cameron DA. Cellular pattern formation in the retina: retinal regeneration as a model system. Mol Vis. 2002:8:280-93.

59. Stenkamp DL, Powers MK, Carney LH, Cameron DA. Evidence for two distinct mechanisms of neurogenesis and cellular pattern formation in regenerated goldfish retinas. J Comp Neurol. 2001;431(4):363-81.

60. Craig SE, Calinescu AA, Hitchcock PF. Identification of the molecular signatures integral to regenerating photoreceptors in the retina of the zebra fish. J Ocul Biol Dis Inform. 2008;1(2-4):73-84.

61. Sifuentes CJ, Kim JW, Swaroop A, Raymond PA. Rapid, dynamic activation of Muller Glial stem cell responses in Zebrafish. Invest Ophthalmol Vis Sci. 2016:57(13):5148-60.

62. Qin Z, Barthel LK, Raymond PA. Genetic evidence for shared mechanisms of epimorphic regeneration in zebrafish. Proc Natl Acad Sci U S A. 2009; 106(23):9310-5.

63. Glaviano A, Smith AJ, Blanco A, McLoughlin S, Cederlund ML, Heffernan T, Sapetto-Rebow B, Alvarez Y, Yin J, Kennedy BN. A method for isolation of cone photoreceptors from adult zebrafish retinae. BMC Neurosci. 2016;17(1): 71.

64. Allison WT, Barthel LK, Skebo KM, Takechi M, Kawamura S, Raymond PA. Ontogeny of cone photoreceptor mosaics in zebrafish. J Comp Neurol. 2011:518(20):4182-95.

65. Tsujimura T, Hosoya T, Kawamura S. A single enhancer regulating the differential expression of duplicated red-sensitive opsin genes in zebrafish. PLoS Genet. 2010;6(12):e1001245.

66. Westphal RE, O'Malley DM. Fusion of locomotor maneuvers, and improving sensory capabilities, give rise to the flexible homing strikes of juvenile zebrafish. Front Neural Circuits. 2013;7:108.

67. McGinn TE, Mitchell DM, Meighan PC, Partington N, Leoni DC, Jenkins CE, Varnum MD, Stenkamp DL. Restoration of dendritic complexity, functional connectivity, and diversity of regenerated retinal bipolar neurons in adult zebrafish. J Neurosci. 2018:38(1):120-36.

68. Kim JW, Yang HJ, Brooks MJ, Zelinger L, Karakulah G, Gotoh N, Boleda A, Gieser L, Giuste F, Whitaker DT, et al. NRL-regulated Transcriptome dynamics of developing rod photoreceptors. Cell Rep. 2016;17(9):2460-73.

69. Kaewkhaw R, Kaya KD, Brooks M, Homma K, Zou J, Chaitankar V, Rao M, Swaroop A. Transcriptome dynamics of developing photoreceptors in threedimensional retina cultures recapitulates temporal sequence of human cone and rod differentiation revealing cell surface markers and gene networks. Stem Cells. 2015;33(12):3504-18.

70. Ogawa Y, Shiraki T, Kojima D, Fukada Y. Homeobox transcription factor Six7 governs expression of green opsin genes in zebrafish. Proc Biol Scie R Soc. 2015;282(1812):20150659

71. Adler R, Raymond PA. Have we achieved a unified model of photoreceptor cell fate specification in vertebrates? Brain Res. 2008;1 192:134-50.

72. Kim JW, Yang HJ, Oel AP, Brooks MJ, Jia L, Plachetzki DC, Li W, Allison WT, Swaroop A. Recruitment of rod photoreceptors from short-wavelengthsensitive cones during the evolution of nocturnal vision in mammals. Dev Cell. 2016:37(6):520-32.

\section{Submit your next manuscript to BioMed Central and we will help you at every step:}

- We accept pre-submission inquiries

- Our selector tool helps you to find the most relevant journal

- We provide round the clock customer support

- Convenient online submission

- Thorough peer review

- Inclusion in PubMed and all major indexing services

- Maximum visibility for your research

Submit your manuscript at www.biomedcentral.com/submit
Biomed Central 